\title{
Indicadores medioambientales y Objetivos de Desarrollo Sostenible (ODS) a revelar por parte de empresas del sector químico
}

\author{
Environmental indicators and Sustainable Development Goals (SDG) to be disclosed \\ by chemical companies
}

Recibido: 23-07-2020 • Aprobado: 06-04-2021 • Página inicial: 151 - Página final: 184

\author{
Juan Manuel Herrera Restrepo* \\ Alvarodiego Ortíz Pérez** \\ Jonatan Pacheco Gutiérrez*** \\ Jaime Andrés Correa García****
}

\begin{abstract}
Resumen: el objetivo del presente artículo consiste en establecer cuáles son los indicadores medioambientales que podrían revelar las empresas del sector químico del Área Metropolitana del Valle de Aburrá. Esto, de modo que las compañías puedan tener insumos alternativos que permitan la creación de informes de sostenibilidad más precisos que satisfagan las necesidades de todos sus stakeholders, llegando así a obtener legitimidad organizacional. Es por eso que se ha hecho un estudio para establecer dichos indicadores, de acuerdo con el Global Reporting Initiative Standards 2016, por medio de técnicas tales como encuestas, entrevistas y la realización de un benchmarking de revelación de indicadores medioambientales con empresas latinoamericanas, identificando su nivel de reporte respecto a cada
\end{abstract}

indicador. También, por medio de este último, se desarrolla un estudio respecto al nivel de adopción de las empresas ante los Objetivos de Desarrollo Sostenible (ODS). En consecuencia, los resultados arrojan que los indicadores que podrían revelar las empresas son emisiones, energía, agua y afluentes y efluentes y residuos; y los ODS a priorizar son igualdad de género, empleo digno, crecimiento económico y acción por el clima. Finalmente, se presentan las conclusiones obtenidas a lo largo de la investigación.

Palabras clave: indicadores medioambientales; Global Reporting Initiative; Objetivos de Desarrollo Sostenible; sector químico; informe de sostenibilidad.

JEL: Q56

\footnotetext{
* Estudiante de Contaduría Pública de la Universidad de Antioquia, Medellín - Colombia. herrerarestrepojuanmanuel@gmail.com ORCID: https://orcid.org/0000-0002-0108-028X

** Estudiante de Contaduría Pública de la Universidad de Antioquia, Medellín - Colombia. alvarodiegoortizperez@gmail.com ORCID: https://orcid.org/0000-0002-5343-4916

*** Estudiante de Contaduría Pública de la Universidad de Antioquia, Medellín - Colombia. jonatan.pachecog@gmail.com ORCID: https://orcid.org/0000-0001-5877-0778

****Profesor Titular del Departamento de Ciencias Contables de la Universidad de Antioquia, Medellín - Colombia. jaime.correa@udea.edu.co ORCID: https://orcid.org/0000-0001-8814-2107
} 


\begin{abstract}
The objective of this article is to establish which are environmental standards could be revealed by companies in the chemical sector of the Metropolitan Area of the Aburrá Valley. This, so that companies can have alternative inputs that allow the creation of more accurate sustainability reports that meet the needs of all their stakeholders, thus coming to obtain organizational legitimacy. That is why a study has been doing to establish these indicators according to the Global Reporting Initiative Standards 2016, through techniques such as survey, interview and conducting a benchmarking of disclosure with environmental indicators with Latin American companies, identifying their level of reporting for each indicator. Also, through the latter, a study is developed on the level of adoption of companies with the sustainable development objectives (SDGs). In consequence, the results show that the indicators that companies could disclose are emissions, energy, water and tributaries and effluents and waste; and the SDGs to prioritize are gender equality, decent employment and economic growth and climate action. Finally, the conclusions obtained throughout the research are presented.
\end{abstract}

Keywords: Environmental standards; Global Reporting Initiative; Sustainable Development Goals; Chemical Sector; Sustainability Report.

\title{
Indicadores ambientais e Objectivos de Desenvolvimento Sustentável (ODS) a serem divulgados pelas empresas químicas
}

Resumo: o objectivo deste artigo é estabelecer quais os indicadores ambientais que poderão ser divulgados pelas empresas do sector químico do Área Metropolitana do Vale do Aburrá. Isto para que as empresas possam dispor de inputs alternativos que permitam a criação de relatórios de sustentabilidade mais precisos que satisfaçam as necessidades de todos os seus stakeholders, ganhando assim legitimidade organizacional. É por isso que foi feito um estudo para estabelecer estes indicadores de acordo com as normas da Global Reporting Initiative 2016, através de técnicas como o levantamento, entrevista e benchmarking do divulgação de indicadores ambientais com empresas latino-americanas, identificando o seu nível de divulgação no que diz respeito a cada indicador. Também, por meio deste último, é desenvolvido um estudo sobre o nível de adopção de empresas com os objectivos do desenvolvimento sustentável (ODS). Consequentemente, os resultados mostram que os indicadores que as empresas poderiam divulgar são as emissões, a energia, a água e os efluentes e resíduos; e as ODS a privilegiar são a igualdade entre homens e mulheres, o emprego decente e o crescimento económico e a acção climática. Por último, são apresentadas as conclusões obtidas ao longo da investigação.

Palavras-chave: indicadores ambientais; Global Reporting Initiative; Objectivos de Desenvolvimento Sustentável; sector químico; relatório de sustentabilidade. 
"Los próximos años serán un período vital para salvar el planeta y alcanzar un desarrollo humano sostenible e inclusivo" (ONU Noticias, 2019).

\section{Introducción}

El calentamiento global y la importancia del cuidado del medio ambiente son temas de alto interés actualmente a nivel mundial. Se considera que la mayoría de los problemas medioambientales relacionados con la contaminación son generados por la actividad industrial de las compañías (Aristizábal, 2018), en especial la industria química que contamina el aire a un nivel equivalente a la de los automóviles (EFE, 2018). Esto conlleva a pensar en iniciativas que apoyen la labor de los entes ambientales mundiales, las cuales también orientarían a las organizaciones, respecto a los principales indicadores, a que sean revelados en un informe de sostenibilidad. Hoy en día, es indispensable pensar en el crecimiento económico sujeto a una producción sostenible y consumo responsable; todo orientado al cuidado de los recursos naturales renovables y no renovables y a la preservación de las especies. Es por eso que el Global Reporting Initiative (GRI) desde el año 2016 se acoge a la guía SDG Compass, impulsando a las empresas a la búsqueda de la alineación de estrategias en pro de la adopción de los ODS. Con base en ello, se ha establecido la inclusión dentro de los informes de sostenibilidad, estrategias encaminadas a la divulgación de los 17 Objetivos de Desarrollo Sostenible (ODS) propuestos por la ONU, debido que "al mantener prácticas comerciales responsables y consistentes con los derechos humanos, trabajo, medio ambiente y anticorrupción, las empresas hacen una contribución para cumplir con los ODS" (Business Reporting on the SDGs, 2017, p. 206).

Los informes de sostenibilidad han ido evolucionando desde sus inicios y han servido para revelar la información que hacen las empresas por la comunidad y el medio ambiente. Para apoyar a la realización de estos, las Naciones Unidas conformó La Red de Pacto Global, la cual es una organización dedicada a promover la Responsabilidad Social Empresarial en las empresas de los países miembros (Marciales, 2018). Dentro de estos se encuentra Colombia, que para el año 2018 contaba con 572 empresas adheridas, de las cuales $33 \%$ eran grandes, $29 \%$ correspondían a pymes y el $38 \%$ restante eran academias, asociaciones de negocios, ciudades, fundaciones, organizaciones sindicales, ONG y entidades del sector público (Pacto Global Red Colombia, 2018).

No obstante, dentro de las empresas asociadas a esta organización, y verificando su base de datos, se pudo identificar que solamente cuatro correspondían al sector químico. Derivado de lo anterior, se desprende el objetivo de este artículo: 


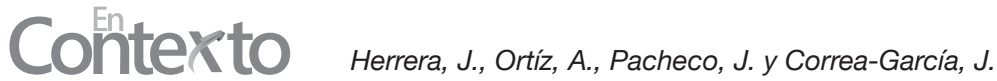

establecer cuáles son los indicadores medioambientales que podrían revelar las empresas del sector químico del Área Metropolitana del Valle de Aburrá; de manera que se pueda llegar a un consenso de cuáles son los mínimos a revelar por parte de estas organizaciones, dando respuesta a la pregunta de investigación: ¿Cuáles indicadores medioambientales podrían revelar las empresas del sector químico del Área Metropolitana del Valle de Aburrá de acuerdo con el Global Reporting Initiative (GRI) y a los ODS?

Además de lo anterior, el artículo se compone de la revisión de la literatura asociada a la teoría de las partes interesadas (stakeholders) y la legitimidad, pasando a la identificación de la estrategia de reporte por parte del GRI con los ODS y continuando con la metodología aplicada. Por otra parte, se muestran los resultados de las encuestas y del benchmarking de indicadores GRI y ODS desarrollado con las empresas argentinas, brasileñas, colombianas, mexicanas y una ecuatoriana. Finalmente, se presentan las conclusiones obtenidas del trabajo realizado.

\section{Marco teórico}

\section{Teoría de la legitimidad y teoría de las partes interesadas (stakeholders)}

La teoría de la legitimidad contribuye a la búsqueda sistemática de las empresas para tener una imagen y posición ante la sociedad dentro de los límites de lo apropiado, lo cual está estrechamente vinculada a la ética y la moral. Respecto a ello, el concepto de legitimidad hace referencia a "una percepción generalizada o una suposición de que las acciones de una empresa son deseables, correctas o apropiadas dentro de algún sistema de normas, valores, creencias y definiciones" (Suchman, 1995, p. 574). Por su parte, Weber (1964) plantea en su libro Economía y Sociedad que la legitimidad se da bajo la dominación, la cual descansa sobre una dominación carismática, entendida como "[...] la entrega extracotidiana a la santidad, heroísmo o ejemplaridad de una persona y a las ordenaciones por ella creadas o reveladas" (p. 197). Scott et al. (2000) indican que "las organizaciones requieren más que recursos materiales e información técnica para sobrevivir y prosperar en sus entornos sociales. Ellos, además necesitan aceptación social y credibilidad" (p. 237).

La teoría de la legitimidad, se basa en la relación empresa-sociedad, donde se entiende que hay "una condición o estatus que emana de la congruencia entre el sistema de valores de una corporación y el de la sociedad de la que forma parte" (Husillos-Carqués, 2007, p. 100), lo que da lugar a que surja un contrato social entre la organización y la sociedad en la que opera (Deegan, 2014). 
Esta teoría enfatiza que la organización debe considerar los derechos del público en general, no solo los de sus inversores, debido a que el incumplimiento de las expectativas sociales puede llevar a que la misma sociedad imponga sanciones (Burhan \& Rahmanti, 2012). Esta desobediencia o carencia de legitimidad da a entender que las empresas no actúan conforme a las normas y valores sociales, lo que también conlleva al fracaso de las mismas (Díez-Martín et al., 2010). Una mala imagen de una compañía ante sus partes interesadas ocasiona una pérdida inminente de clientes, lo que a la larga genera un bajo posicionamiento de esta en el mercado (Díez-Martín et al., 2014); puesto que una baja reputación organizacional obtenida frente a los interesados más cercanos, influirá rápidamente en mayor parte de la sociedad en general (Jones, 1995).

Para hacerle frente a la mala reputación, las empresas buscan la legitimidad por medio de acciones caritativas en favor de la sociedad, y también la buscan por medio de la cooptación (Dowling \& Pfeffer, 1975). Este sistema de valores articulados, a menudo denominado como "contrato social", se compone de las expectativas de los diversos stakeholders, donde estos para conocer el desempeño de las organizaciones usan el término de la "auditoría social" (Deegan, 2014).

Apuntando a lo anterior, se gesta una relación con otra teoría, la cual va muy relacionada con la legitimidad, pero que se enfoca más en las personas relacionadas con las compañías. Es por ello que Freeman (1984) definió el concepto de persona relacionada o stakeholder como cualquier individuo o grupo de personas que es o se verá afectado por el logro de los objetivos de una empresa.

Este concepto también puede ser visto como alguien que de manera explícita o Este concepto también puede ser visto como alguien que de manera explícita o implícita, voluntaria o involuntaria realiza una apuesta al poner algo en juego en la marcha de una organización (Fernández y Bajo, 2012). “Generalmente se considera que los inversores son los principales interesados, es decir, que pertenecen a los grupos más importantes que una empresa debe abordar, además de las comunidades, clientes, empleados y proveedores" (Lock \& Seele, 2015, p. 116). Estos se reúnen en grupos de interés: intereses materiales, políticos, afiliación o permanencia, relacionados con la información, simbólicos e intereses metafísicos o espirituales (Fernández y Bajo, 2012), en donde se requiere de iniciativas grupales e intereses generalizables, en los cuales no solo se abarquen las ideas de los principales stakeholders, sino que se logre identificar las ideas de aquellos que de una u otra forma resulten siendo afectados por el desarrollo del objeto social de la compañía (González, 2007). 


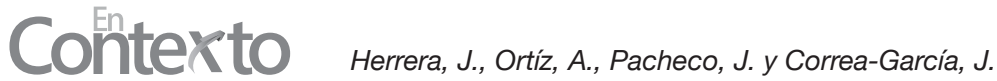

Esta teoría presenta tres tipos de funcionalidades: Descriptiva-empírica, la cual busca describir y explicar la naturaleza de la empresa, así como el juicio de los miembros de la junta sobre los intereses de la empresa y como esta está siendo gestionada; la segunda, funcionalidad instrumental, es la recolección de la información tomada en el uso descriptivo para identificar las relaciones dadas entre la gestión de los stakeholders y el logro de los objetivos corporativos; por último, la normativa donde se busca interpretar las funciones que tienen las empresas para la identificación de las pautas morales y filosóficas para la operación y gestión de las mismas (Donaldson \& Preston, 1995).

En este sentido, Deegan (2014) plantea que los stakeholders tienen el derecho a ser informados en cuanto a la forma que están siendo afectados por todas las actuaciones de la organización, tanto de forma positiva, la generación de empleo, como negativamente, la contaminación. Además, Wicks et al. (1994) indican que es necesario involucrar todos los grupos de interés sin distinción. De este modo, se establece que el objetivo de la empresa es servir a todos sus agentes sociales (VacaAcosta et al., 2007) y que puede ser llevado a cabo a través de la elaboración de informes de responsabilidad social corporativa (RSC), con los cuales se pretende mantener informados a los stakeholders sobre el actuar de la compañía respecto a aspectos económicos, sociales y ambientales (González, 2007).

\section{EI reporte de los ODS en los informes de sostenibilidad bajo GRI}

Una de las metodologías más aceptadas para la divulgación de información sostenible de las empresas es la creada por The Global Reporting Initiative, conocida como GRI. Esta metodología nace con la iniciativa conjunta de organizaciones no gubernamentales estadounidenses CERES (Coalition for Environmentally Responsible Economies) y el PNUMA (Programa de las Naciones Unidas para el Medio Ambiente), con el objetivo de apoyar a las organizaciones a entender la importancia de los reportes sostenibles a través de la calidad, el rigor y la utilidad de los reportes de sostenibilidad (Arias-Alosilla y Linares-Romero, 2008).

Los reportes bajo esta metodología son usados para comparar el desempeño de las organizaciones en cuanto a las leyes, normas, códigos, estándares de desempeños e iniciativas voluntarias y para demostrar el compromiso organizacional con el desarrollo sostenible (Burhan \& Rahmanti, 2012).

Los ODS y los estándares del GRI son procesos articulados y deben ser comunicados entre sus grupos de interés, es decir, el propósito del estándar GRI está alineado con prácticas empresariales enfocadas hacia el equilibrio económico, social y 
ambiental. Es en este punto donde los ODS se relacionan para configurar el plan de acción en favor de las personas (Asamblea General de las Naciones Unidas, 2015). Finalmente, los ODS y todos los estándares GRI a nivel mundial tienen un objetivo en común: la comunicación para el desarrollo, impulsando a la sociedad en general a la apropiación de los problemas (Comunicación Activa, 2019).

Aun así, las estrategias del GRI y ODS son particulares y muy diversas, además de ser las más aceptadas a nivel internacional, en especial el GRI debido a que facilita un marco para la elaboración de memorias de sostenibilidad, basado en la credibilidad, consistencia y comparación (Rodríguez-Guerra y Ríos-Osorio, 2016).

El GRI tiene como misión, "[...] satisfacer esta necesidad al proporcionar un marco confiable y creíble para la presentación de informes de sostenibilidad que pueda ser utilizado por organizaciones de cualquier tamaño, sector o ubicación" (Burhan \& Rahmanti, 2012, p. 262), orientándose al desarrollo sostenible de las organizaciones y corporaciones desde tres aspectos: el aspecto económico, ambiental y social. El primer aspecto posibilita la toma de conciencia sobre el desempeño e impacto financiero; el segundo orienta los impactos directos e indirectos en la producción y la prestación de los servicios; finalmente, el aspecto social mejora las condiciones internas y externas de los seres humanos (Rodríguez-Guerra y Ríos-Osorio, 2016).

De acuerdo con los autores Rodríguez-Guerra y Ríos-Osorio (2016), la metodología GRI abarca siete estrategias:

1. Estrategia y análisis: es fundamental en este paso que el representante o responsable de la organización o colectivo socialice la visión, la estrategia a corto, mediano y largo plazo.

2. Perfil de la organización: es fundamental describir la imagen y características de la organización para identificar la formalización, la estructura y el tipo de productos o servicios que ofrecen.

3. Identificación de aspectos materiales y cobertura de la memoria: la organización precisa cobertura y aspectos materiales para incluir en la memoria.

4. Participación de los grupos de interés: se analiza la pertinencia, identificación y relacionamiento con la organización.

5. Perfil de la memoria: se presenta la información básica de la memoria y la verificación externa.

6. Gobierno: se tienen en cuenta aspectos de composición, funciones, estructura de gobierno, papel del órgano superior, entre otras.

7. La ética e integridad: se socializan los valores, los principios, los estándares y las normas de la organización. 


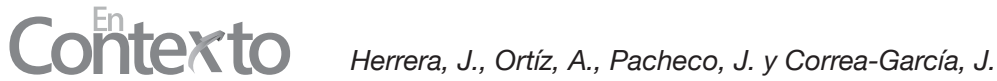

También la metodología GRI enmarca un criterio de gran relevancia para la elaboración de informes de sostenibilidad, denominado como "materialidad". Según Global Sustainability Standards Board (GSSB) (2016), es un principio para la elaboración de informes de acuerdo con su contenido, y es definido como "el principio que determina qué temas relevantes son suficientemente importantes como para que sea esencial presentar información al respecto" (p. 10).

Los reportes bajo esta metodología "buscan entregar datos cuantitativos y cualitativos que den cuenta del comportamiento social, medioambiental y económico de las empresas" (Gómez-Villegas y Quintanilla, 2012, p. 126).

El objetivo del GRI, el cual enfatiza en el desarrollo sostenible, está encaminado al propósito que tiene las Naciones Unidas en mitigar problemas sociales, ambientales y económicos como la pobreza extrema y la desigualdad (Bertazzi et al., 2016).

Los ODS nacen de los Objetivos de Desarrollo del Milenio (ODM), estos últimos fueron creados y presentaron su ejecución entre los años 2000-2015 para abordar la problemática de la pobreza. Durante este período, los ODM se encaminaron a la lucha contra enfermedades, disminución de la mortalidad infantil y acceso al agua potable, entre otras problemáticas existentes; por lo que para el año 2015, se procede a la creación de los ODS: 17 objetivos interrelacionados, con el fin de continuar con el abordaje y solución de problemas urgentes que se estuvieran presentando en la sociedad para el 2030 (PNUD, 2019).

Estos objetivos fueron creados de tal forma que fueran aplicados tanto para países en desarrollo como desarrollados y, a la vez, para reunir a las organizaciones y lograr un desarrollo sostenible en torno a un marco en común; por lo que cada objetivo está compuesto por metas e indicadores que permitirán medir el nivel de adopción de estos para el 2030 (Bertazzi et al., 2016).

De acuerdo con el PNUD (2015) world leaders agreed to 17 Global Goals (officially known as the Sustainable Development Goals or SDGs, estos objetivos tienen los siguientes fines:

- Objetivo 1: Fin de la pobreza: poner fin a la pobreza en todas sus formas en todo el mundo.

- Objetivo 2: Hambre cero: poner fin al hambre, lograr la seguridad alimentaria y la mejora de la nutrición y promover la agricultura sostenible.

- Objetivo 3: Salud y bienestar: garantizar una vida sana y promover el bienestar para todos en todas las edades. 
- Objetivo 4: Educación de calidad: garantizar una educación inclusiva, equitativa y de calidad y promover oportunidades de aprendizaje durante toda la vida para todos.

- Objetivo 5: Igualdad de género: lograr la igualdad entre los géneros y empoderar a todas las mujeres y las niñas.

- Objetivo 6: Agua limpia y saneamiento: garantizar la disponibilidad de agua y su gestión sostenible y el saneamiento para todos.

- Objetivo 7: Energía asequible y no contaminante: garantizar el acceso a una energía asequible, segura, sostenible y moderna para todos.

- Objetivo 8: Trabajo decente y crecimiento económico: promover el crecimiento económico sostenido, inclusivo y sostenible, el empleo pleno y productivo y el trabajo decente para todos.

- Objetivo 9: Industria, innovación e infraestructura: construir infraestructuras resilientes, promover la industrialización inclusiva y sostenible y fomentar la innovación.

- Objetivo 10: Reducción de las desigualdades: reducir la desigualdad en y entre los países.

- Objetivo 11: Ciudades y comunidades sostenibles: lograr que las ciudades y los asentamientos humanos sean inclusivos, seguros, resilientes y sostenibles.

- Objetivo 12: Producción y consumo responsables: garantizar modalidades de consumo y producción sostenibles.

- Objetivo 13: Acción por el clima: adoptar medidas urgentes para combatir el cambio climático y sus efectos.

- Objetivo 14: Vida submarina: conservar y utilizar en forma sostenible los océanos, los mares y los recursos marinos para el desarrollo sostenible.

- Objetivo 15: Vida de ecosistemas terrestres: gestionar sosteniblemente los bosques, luchar contra la desertificación, detener e invertir la degradación de las tierras y detener la pérdida de biodiversidad

- Objetivo 16: Paz, justicia e instituciones sólidas: promover sociedades justas, pacíficas e inclusivas.

- Objetivo 17: Alianzas para lograr los objetivos: revitalizar la Alianza Mundial para el Desarrollo Sostenible (PNUD, 2015,)world leaders agreed to 17 Global Goals (officially known as the Sustainable Development Goals or SDGs.

Es por esto que los ODS son necesarios para el desarrollo sustentable en cuanto abarcan problemas que afectan a toda la población y "nos invitan a todos a crear un planeta más sostenible, seguro y próspero para la sociedad” (PNUD, 2019). 


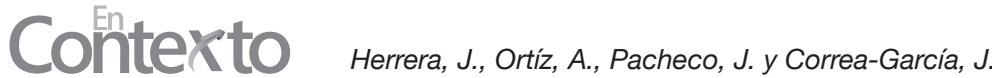

\section{Generalidades del sector químico}

Este artículo se contextualiza en el sector químico, el cual es uno de los subsectores de la industria manufacturera denominada como la de mayor consumo de recursos naturales no renovables; además, es una de las más contaminantes (Aristizábal, 2018).

Uno de los motivos por el cual este sector está catalogado dentro de este índice radica en que la elaboración de la mayoría de sus productos y sustancias se basa en la explotación de combustibles fósiles, generando así gases efecto invernadero. Estos productos se conocen y clasifican como química básica (basada en la petroquímica, los polímeros y la química inorgánica básica), química especializada (donde se encuentran en su mayoría productos para la protección de cosechas, tintes y colorantes) y química para la industria y el consumo final (detergentes, jabones y otros artículos de aseo) (Montes-Valencia, 2015).

Este sector, se ramifica en otros subsectores, los cuales, a su vez, y de acuerdo con la Clasificación Industrial Internacional Uniforme (CIIU), se articulan en 4 divisiones, conformando 4 grupos divididos en 12 clases.

Estas divisiones presentan ciertos rangos, donde la máxima categoría es la correspondiente al número 20, denominada como fabricación de sustancias y productos químicos. Esta se divide en 3 grupos, los cuales conforman 9 clases.

Por otro lado, las divisiones restantes, con excepción de la 21, solo se conforman de una clase destinada al comercio de los productos y sustancias químicas y a la extracción de otras minas y canteras que se denominan con los números 41 y 08 respectivamente. El caso de la división 21, se conforma por un grupo que a su vez lo constituye una clase que abarca la fabricación de productos farmacéuticos, sustancias químicas medicinales y productos botánicos de uso farmacéutico.

Por otra parte, en Colombia, el sector químico ha presentado muy buenos resultados en el período comprendido entre los años 2000-2018, arrojando una tasa de crecimiento anual compuesto ${ }^{1}$ del $11,7 \%$ anual (Colombia Productiva y PricewaterhouseCoopers, 2019).

No obstante, el sector actualmente presenta un déficit comercial, puesto que las importaciones han crecido un $0,6 \%$ respecto a las exportaciones que arrojaron un resultado de 3,1\%, durante el período 2014-2018 (Colombia Productiva y PricewaterhouseCoopers, 2019).

\footnotetext{
${ }^{1}$ Compound Anual Growth Ratio.
} 
En los últimos años, se han venido desarrollando estrategias garantes de innovación y sostenibilidad, que van desde el potenciamiento orientado a la biotecnología, bioproductos farmacéuticos y bioenergía, entre otros (Colciencias, 2019).

Sumado a lo anterior, también es importante destacar los avances en bioquímica, biomimética, biomateriales, bioingredientes y bioinsumos; por lo que, por medio de estos, se pretende la producción de plásticos biodegradables, el aprovechamiento de residuos orgánicos para su posterior reutilización y reducción de desechos contaminantes altos en carbono (Aristizábal, 2018).

\section{Metodología}

\section{Obtención de muestras}

Para dar respuesta al planteamiento, se procedió a realizar una investigación de método inductivo donde se seleccionaron dos muestras: La primera compuesta por empresas químicas latinoamericanas que reportan información a la base de datos del GRI (GRI Database) y no cotizantes en la bolsa de valores mundial y de sus respectivos países; esto con el fin de conocer el nivel de reporte de los indicadores medioambientales de este tipo de empresas en los países de la región mencionada y tabular dicha información de modo que fuese comparable con el nivel de reporte de las empresas químicas del Área Metropolitana del Valle de Aburrá.

Para llevar a cabo dicho análisis fue necesario seleccionar una muestra de empresas latinoamericanas, tomadas de los cinco primeros países que mostraban el índice más alto de organizaciones químicas y de cuidado de la salud en la GRI Database. En la Figura 1 se observa el nivel de reporte de las empresas por países latinoamericanos; es por ello que las empresas seleccionadas fueron de los siguientes países: Argentina, Brasil, Colombia, Ecuador y México, los cuales sumaban un porcentaje acumulado de $89,61 \%$ a nivel de Pareto. 


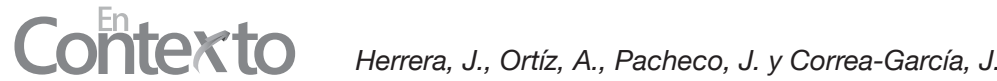

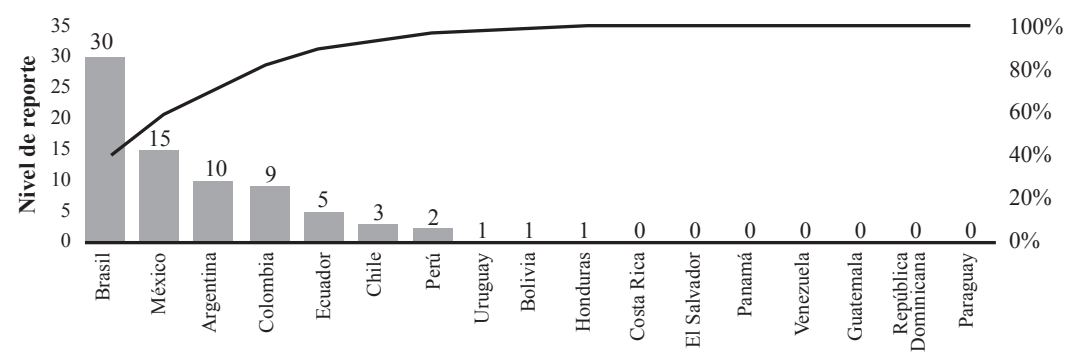

Países

Figura 1. Incidencia de publicación de memorias en cada país

Elaboración propia con base al GRI Database.

Tabla 1

Empresas seleccionadas de países latinoamericanos

\begin{tabular}{|c|c|}
\hline País & Empresas \\
\hline \multirow{3}{*}{ Argentina } & Dow Argentina. \\
\hline & Profertil. \\
\hline & Savant. \\
\hline \multirow{10}{*}{ Brasil } & Quimicryl. \\
\hline & Iharabras. \\
\hline & Oxiteno. \\
\hline & Eurofarma. \\
\hline & Aché Laboratorios. \\
\hline & Cosmotec. \\
\hline & Dow Brasil. \\
\hline & Daiichi Sanyko Brasil. \\
\hline & Roche Brasil. \\
\hline & Sanofi Brasil. \\
\hline \multirow{2}{*}{ Colombia } & Antek. \\
\hline & Roche Colombia. \\
\hline Ecuador & Yanbal Ecuador. \\
\hline \multirow{4}{*}{ México } & Liomont. \\
\hline & Pfizer México. \\
\hline & Grupo Petrotemex. \\
\hline & Praxair México. \\
\hline
\end{tabular}

Elaboración propia con base en GRI Database. 
Con los países seleccionados, se procedió a escoger las empresas del sector químico, las cuales habían reportado por lo menos un informe de sostenibilidad desarrollado bajo los estándares del Global Reporting Initiative, en GRI Database, en un intervalo de tiempo comprendido entre los años 2013 y 2018. La Tabla 1 muestra las empresas químicas latinoamericanas que cumplieron los dos requisitos anteriores, las cuales fueron diez brasileñas, cuatro mexicanas, tres argentinas, dos colombianas y una ecuatoriana.

Es importante resaltar que no todas las empresas presentaron su versión bajo la versión GRI Standards, sino que algunas lo desarrollaron bajo la versión anterior, la cual era GRI G4, por lo que fue necesario realizar un mapping² a estos últimos para saber qué indicadores GRI Standards estaban presentando.

En consecuencia, para la recolección de la información, se descargó el reporte de sostenibilidad más actualizado que estuviese en la GRI Database, de las empresas seleccionadas y se observó el nivel de reporte para cada uno los indicadores propuestos en la guía GRI, por lo que resultó pertinente buscar el glosario de reporte de este tipo de indicadores. Posteriormente. se procedió a tabular la información en una hoja de cálculo, en la cual se realizó una codificación binaria para cada indicador de la serie ambiental del GRI, donde los que fueran revelados se le asignaría el número "1" y los que no fueran revelados se le asignaría el número "0". Esto último, se llevó a cabo para cada una de las compañías de la muestra, obteniendo información de cuáles eran los indicadores con mayor presencia en los informes de las empresas latinoamericanas.

Con la tabulación de los datos plasmada en la hoja de cálculo, se procedió a realizar un índice de la serie ambiental del GRI frente a las empresas latinoamericanas, lo cual se llevó a cabo totalizando cada uno los indicadores y comparándolos sobre el total de los mismo de la mencionada serie, posteriormente los índices que arrojaron cada una de las empresas se promediaron en cuatro grupos: el primero, compuesto por las empresas brasileñas; el segundo, por las empresas mexicanas; el tercero, por las empresas argentinas; y el cuarto contiene las restantes de la muestra (Colombia y Ecuador), las cuales se agruparon de acuerdo con la común participación en calidad de países miembros dentro de la Comunidad Andina. Este pacto busca "alcanzar un desarrollo integral, equilibrado y autónomo, mediante la integración andina, con proyección hacia una integración sudamericana y latinoamericana" (Comunidad Andina, s. f.).

\footnotetext{
${ }^{2}$ El mapping G4 to GRI Standards es un documento que muestra el indicador G4 representado en GRI Standards 2016, obtenido de www.globalreporting.org.
} 


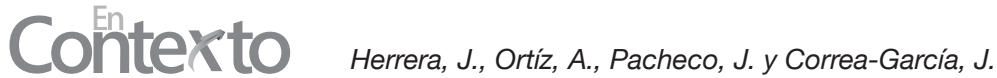

Cabe mencionar que la anterior muestra sirvió también para llevar a cabo un estudio adicional al objetivo de investigación propuesto, orientado al nivel de reporte de los ODS por parte de estas empresas. El motivo para llevarlo a cabo fue que la última versión del GRI, emitida en el 2016 (GRI Standards 2016), buscaba que las empresas publicaran dentro del informe de sostenibilidad información relacionada a los ODS propuestos por la ONU.

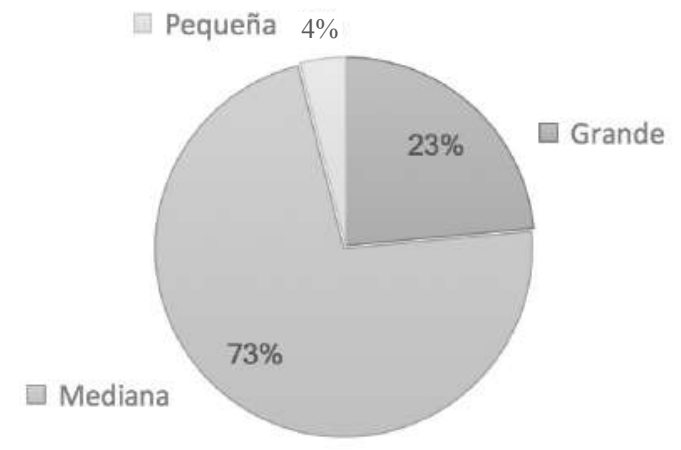

Figura 2. Tamaño de las empresas químicas no cotizantes del Área Metropolitana del Valle de Aburrá

Elaboración propia con base en Supersociedades.

La segunda muestra corresponde a empresas químicas del Área Metropolitana del Valle de Aburrá, conformada en su mayoría por grandes y medianas empresas, las cuales permitirían conocer el alcance que presentan en esta región para reportar indicadores medioambientales y así realizar un análisis de estos resultados con lo obtenido en el benchmarking. Para llevar a cabo la selección de la muestra, se utilizó la base de datos (Portal de información empresarial (PIE)) de la Superintendencia de Sociedades puesto que, al ser un ente de vigilancia y control, las empresas del sector químico (particularmente) le deben reportar información financiera.

Las características necesarias para ser catalogadas en la muestra fueron: en primer lugar, pertenecer al Área Metropolitana del Valle de Aburrá; en segundo lugar, su actividad principal debía corresponder a una actividad asociada al uso de sustancias químicas de acuerdo con el Código Industrial Internacional Uniforme (CIIU).

Las empresas químicas que cumplieron con las dos características anteriores fueron 51, y su actividad principal fue catalogada en la división 20 y 21 del CIIU. 
Posteriormente, se procedió a hacer una clasificación de estas de acuerdo con el total de activos brutos, basado en la Ley 905 de 2004; lo que arrojó como resultado el descrito en la Figura 3, en donde el $73 \%$ de empresas es de tamaño mediano (5001-30000 SMLMV), seguida de un 23\% en empresas de gran tamaño (más de 30000 SMLMV) y finalmente tan solo el $4 \%$ del total son pequeñas empresas (501-5000 SMLMV).

No todas estas empresas están ubicadas en el mismo municipio de la región del Área Metropolitana del Valle de Aburrá. La Figura 3 muestra que la mayoría de estas (23) se encuentra ubicada en la ciudad de Medellín; seguido por los municipios de Sabaneta, Itagüí (Zonas industriales) y Envigado; los cuales cuentan con (9), (8) y (6) respectivamente.

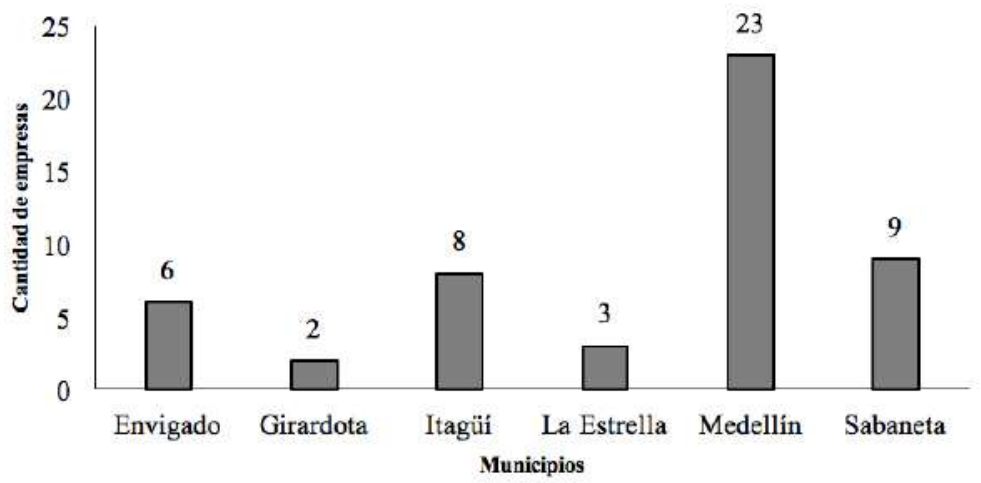

Figura 3. Empresas químicas clasificadas por municipio

Elaboración propia con base a Supersociedades.

También es importante mencionar que los municipios ubicados en los extremos, al norte y sur del Área Metropolitana del Valle de Aburrá (Girardota y la Estrella), son los que menos empresas químicas poseen, con un 3,92\% y 5,88\% respectivamente. Consecuentemente, de las 51 empresas identificadas, al hablar de división del sector químico, la mayoría pertenece a la división 20 , pero que, al momento de desglosarlas por grupo, la fabricación de productos farmacéuticos, sustancias químicas medicinales y productos botánicos de uso farmacéuticos (Grupo 2100) posee un mayor peso porcentual $(23,53 \%)$. 


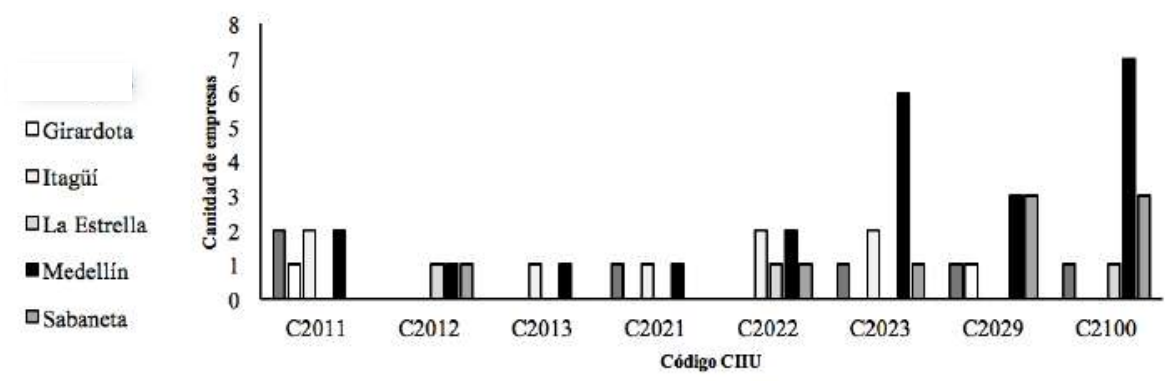

Figura 4. Distribución empresas por códigos CIIU

Elaboración propia con base en Supersociedades.

Tabla 2

Códigos CIIU

\begin{tabular}{llc}
\hline & \multicolumn{1}{c}{ Código CIIU } & Empresas \\
\hline C2011 & Fabricación de sustancias y productos químicos básicos. & 7 \\
\hline C2012 & Fabricación de abonos y compuestos inorgánicos nitrogenados. & 3 \\
\hline C2013 & Fabricación de plásticos en formas primarias. & 2 \\
\hline C2021 & Fabricación de plaguicidas y otros productos químicos de uso agropecuario. & 3 \\
\hline C2022 & $\begin{array}{l}\text { Fabricación de pinturas, barnices y revestimientos similares, tintas para } \\
\text { impresión y masillas. }\end{array}$ & 6 \\
\hline C2023 & $\begin{array}{l}\text { Fabricación de jabones y detergentes, preparados para limpiar y pulir; } \\
\text { perfumes y preparados de tocador. }\end{array}$ & 10 \\
\hline C2029 & Fabricación de otros productos químicos n.c.p. & 8 \\
\hline C2100 & $\begin{array}{l}\text { Fabricación de productos farmacéuticos, sustancias químicas medicinales } \\
\text { y productos botánicos de uso farmacéutico. }\end{array}$ & 12 \\
\hline
\end{tabular}

Elaboración propia con base a Supersociedades.

Seguido por las empresas del grupo C2023 (Fabricación de jabones y detergentes, preparados para limpiary pulir; perfumes y preparados de tocador) con un 19,61\% que hace referencia a bienes de química para la industria y consumo final. Ambos grupos como se observa en la Figura 4, tienen una mayor presencia en el municipio de Medellín. 
Los productos químicos del grupo C2029 (Fabricación de otros productos químicos), con ocho empresas (16\%), ocupan el tercer puesto de la tabla, y que, al observar su ubicación, están distribuidas entre los municipios de Medellín, Sabaneta, Girardota y Envigado.

Seguidamente, se encuentra el grupo C2011 (Fabricación de sustancias y productos químicos básicos) y C2022 (Fabricación de pinturas, barnices y revestimientos similares, tintas para impresión y masillas) con un $13,73 \%$ y $11,76 \%$ respectivamente. Por otra parte, los grupos C2012 (Fabricación de abonos y compuestos inorgánicos nitrogenados) y C2021 (Fabricación de plaguicidas y otros productos químicos de uso agropecuario) comparten un mismo porcentaje de 5,88\%; para finalizar con un 3,92\% correspondiente a dos empresas del grupo C2013 (Fabricación de plásticos en formas primarias).

\section{Diseño de instrumento aplicado a las empresas del sector químico}

El instrumento llevado a cabo para la segunda muestra es un cuestionario desarrollado bajo la técnica de la encuesta, el cual está divido en cuatro secciones y compuesto por 11 interrogantes. La primera parte se fundamenta en conocer datos generales de las compañías químicas y cuáles informes financieros y no financieros fueron elaborados y revelados por ellos. La segunda parte se enfoca en el grado de conocimiento y revelación de los ODS por parte de las empresas químicas. La tercera parte, y más importante, es un cuestionario acerca sobre el grado de conocimiento que tienen las empresas de los indicadores medioambientales GRI y la capacidad de revelación de estos.

Además del anterior, se llevó a cabo una entrevista semiestructurada en el Área Metropolitana del Valle de Aburrá, la cual cuestionaba acerca de los reportes exigidos a las empresas químicas de este sector del departamento de Antioquia, los ODS a priorizar dentro de esta industria, los programas y estrategias medioambientales, entre otros temas (estos instrumentos, se encuentran en los anexos del presente artículo).

\section{Resultados y discusión}

La divulgación de los reportes sostenibles por parte de las empresas da a conocer el nivel de revelación que estas tienen de cada uno de los estándares ambientales del GRI y de los ODS; así como aquellos indicadores de mayor incidencia, y los objetivos sostenibles priorizados, de manera que se enfoquen al logro y desarrollo de sus metas y de su objeto social. En este sentido, Global Reporting Initiative, 


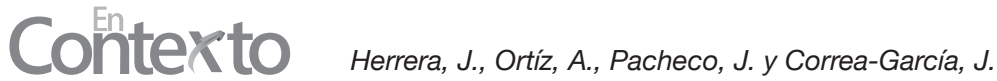

ATKearney, y Liga de directores (2016) mencionan en la encuesta denominada Direccionando la sostenibilidad desde el directorio que el $75 \%$ de los directorios de las compañías manifestaron que la sostenibilidad debería ser un tema predominante en la estrategia empresarial.

De acuerdo con ello, la presente investigación arrojó los siguientes resultados que muestran el nivel de reporte de los indicadores medioambientales y publicación de los ODS en las empresas de los países seleccionados; así como el conocimiento y capacidad que consideran las empresas químicas del Área Metropolitana del Valle de Aburrá que dieron respuesta al instrumento aplicado, tener para la revelación de información sostenible de acuerdo con los estándares ambientales del GRI como de los ODS.

\section{Nivel de reporte de indicadores por parte de las empresas latinoamericanas}

Como se ha mencionado anteriormente, los informes de sostenibilidad son un medio en el que las empresas podrían divulgan su actuar sostenible (positivo o negativo) de acuerdo con las exigencias de información de los stakeholders (Heredia-Rodríguez y Gómez-Jiménez, 2011); además, es un “[...] instrumento útil [...] las organizaciones rinden cuentas a los grupos de interés sobre su contribución al objetivo del desarrollo sostenible" (Palacios y Coppa, 2015, p. 235). Este ha llegado a convertirse en una actividad necesaria desde la óptica de los agentes de interés, observar el nivel de desempeño de estas respecto a los estándares propuestos por el GRI.

De acuerdo con ello, se muestra el nivel de reporte de cada indicador medioambiental por parte de las empresas latinoamericanas con base al benchmarking desarrollado de acuerdo con sus informes de sostenibilidad publicados los datos del GRI.

Es importante destacar que los resultados respecto a la emisión de informes de sostenibilidad presentados por parte de las compañías no son garantía de adopción por parte de estas; sin embargo, son un indicio de que la empresa se muestra comprometida con lo planteado por el GRI. Además, "[...] no existe en verdad una empresa responsable, sino que hay empresas que tienen prácticas de responsabilidad, con mayor o menor impacto, con mayor o menor efectividad" (Vives, 2013, p. 193). 


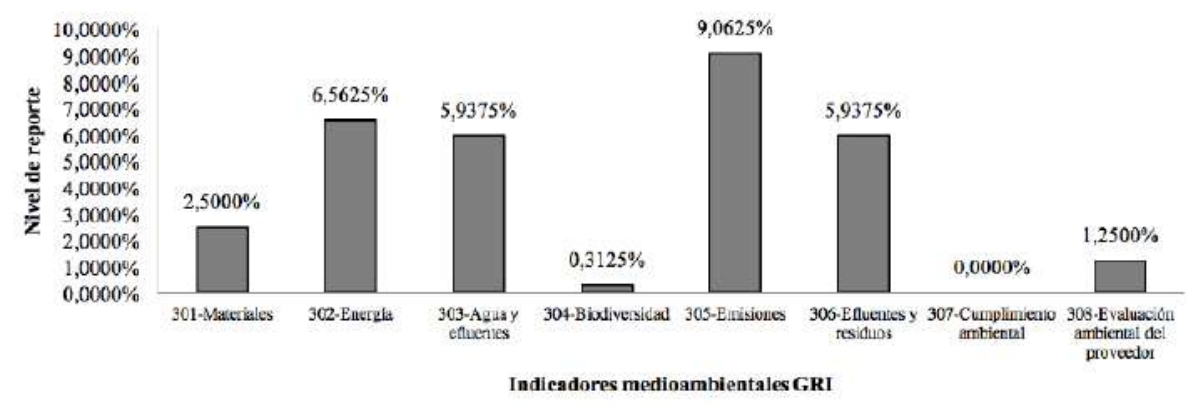

Figura 5.Cumplimiento de las empresas químicas brasileñas

Elaboración propia con base al GRI Database.

En primer lugar, respecto a las empresas del gigante suramericano, se presentan resultados analizados de mayor a menor, respecto al nivel de reporte. De acuerdo con esto, la situación más favorable se da para los intereses de los indicadores 305-Emisiones y 302-Energía, continuando con los estándares 303-Agua y efluentes y 306-Efluentes y residuos, y mostrando los números más bajos ante los similares 301-Materiales, 308-Evaluación ambiental del proveedor, 304-Biodiversidad y 307-Cumplimiento ambiental.

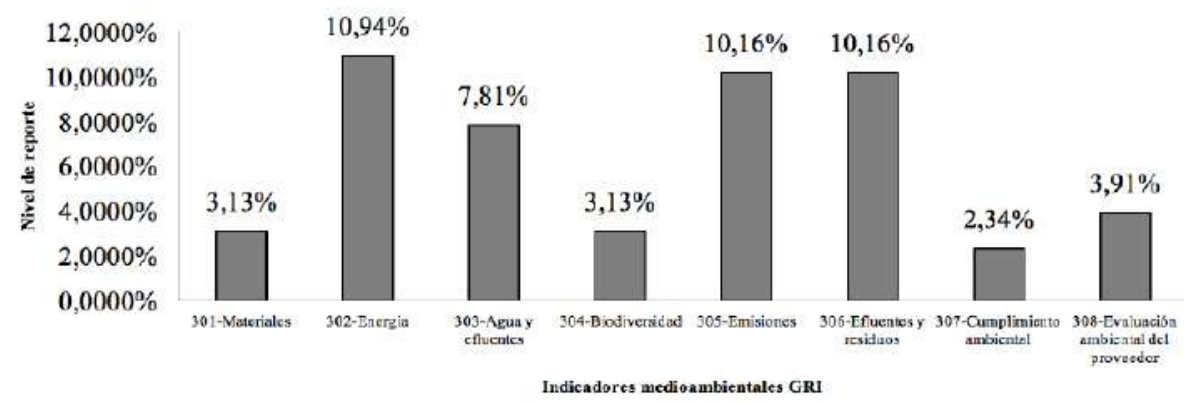

Figura 6. Nivel de reporte de indicadores medioambientales empresas químicas mexicanas Elaboración propia con base en GRI Database.

Por otra parte, las empresas mexicanas analizadas arrojan un resultado un poco similar, debido que los indicadores con mayor reporte son: 302-Energía, 305-Emisiones, 306-Efluentes y residuos con un porcentaje similar y, en tercer lugar, 303-Agua y efluentes. Finalmente, se muestran los indicadores con menor incidencia: 308-Evaluación ambiental del proveedor, 307- Cumplimiento ambiental, 301-Materiales y 304-Biodiversidad. 


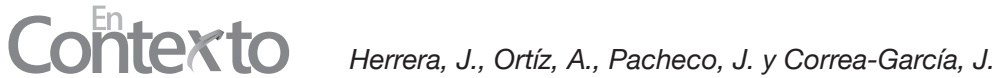

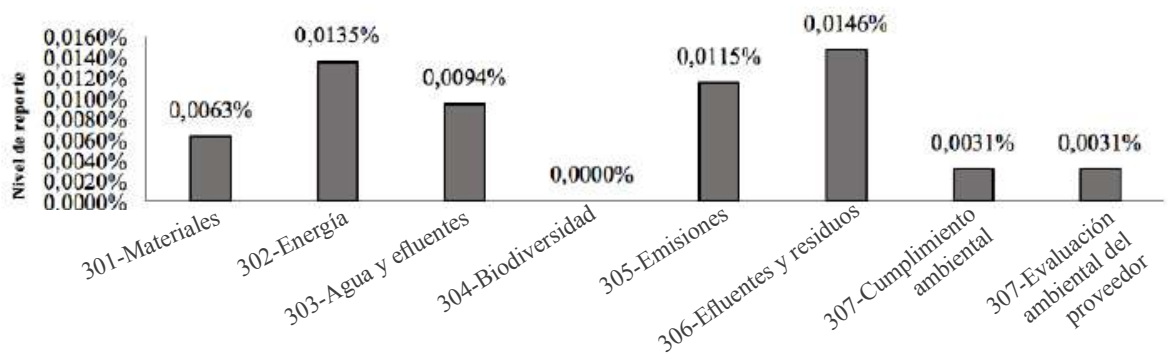

Indicadores ambientales GRI

Figura 7. Nivel de reporte de indicadores medioambientales empresas argentinas Elaboración propia con base en GRI Database.

Respecto a las empresas Argentinas, se observa que los indicadores más revelados (mayores a $0,01 \%$ ) son 306-Efluentes y residuos, con un $0,0146 \%$; posteriormente, 302-Energía con un 0,0135\%; finalmente, 305-Emisiones que, a su vez, muestra un porcentaje de $0,0115 \%$. Por otra parte, se identifica que el indicador con menor nivel de revelación es el 304-Biodiversidad, puesto que su resultado es nulo.

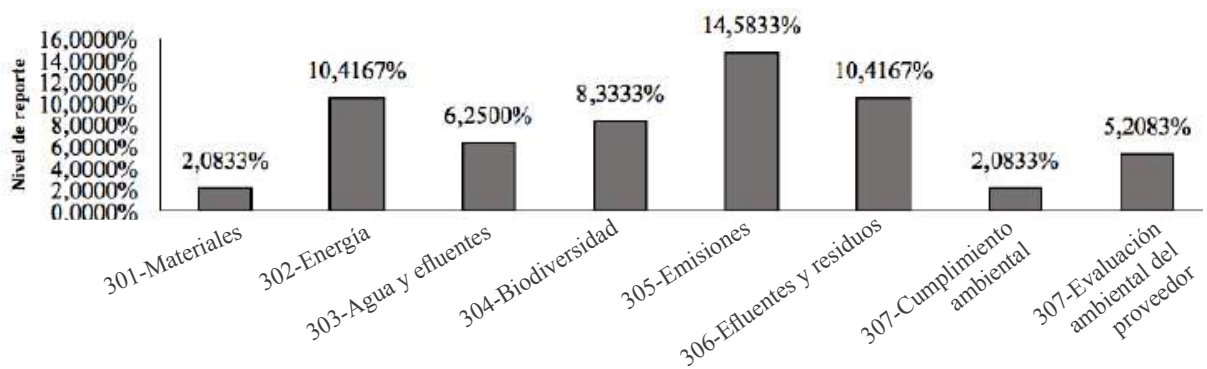

Indicadores ambientales GRI

Figura 8. Nivel de reporte de indicadores medioambientales empresas colombianas y una ecuatoriana

Elaboración propia con base en GRI Database.

Respecto al resto de países, entre los cuales se encuentran Colombia y Ecuador, se identifica que los indicadores con mayor nivel de adopción (mayores a 10\%) son 305-Emisiones, el cual arroja un 14,5833\%; luego 302-Energía y 306-Efluentes y 
residuos comparten el mismo resultado 10,4167\%; finalmente. se muestra un bajo 2,0833\% de los indicadores 301-Materiales y 307-Cumplimiento ambiental.

Al efectuar el recuento general, se identificó que, en promedio, las empresas químicas latinoamericanas seleccionadas cumplen en un 44,0956\% los indicadores medioambientales del total propuesto por el GRI, superado por los indicadores económicos en una cantidad bastante baja y superando los indicadores sociales en una ínfima cantidad. En este punto, particularmente se observa que estas reportan información específicamente de los indicadores medioambientales, cuya temática compromete en gran medida a su industria. Tal es el caso de los indicadores 302-Energía, gracias a que actualmente hay una alta preocupación internacional frente al tema de la gestión energética por su alto nivel de contaminación (Berenguer et al., 2019); 305-Emisiones, puesto que los efectos nocivos producidos por la industria química en la actualidad son bastante elevados, y generan alteraciones en la salud humana y en los ecosistemas del mundo (De la Cruz-Monte et al., 2011). También se observa que 303-Agua y efluentes y 306-Efluentes y residuos tienen un alto nivel de revelación; de acuerdo con Becerra y Espinoza (2002), la degradación química y un inadecuado manejo de residuos industriales provocan una pérdida irreparable de los suelos y el agua, respectivamente.

Entonces, es pertinente suponer que las empresas del sector químico del Área Metropolitana del Valle de Aburrá, al igual que las compañías latinoamericanas seleccionadas, presentan su informe de sostenibilidad priorizando y detallando sus indicadores materiales; de forma que los stakeholders reciban una información más profunda respecto a estos, pero este interrogante se resolverá más adelante.

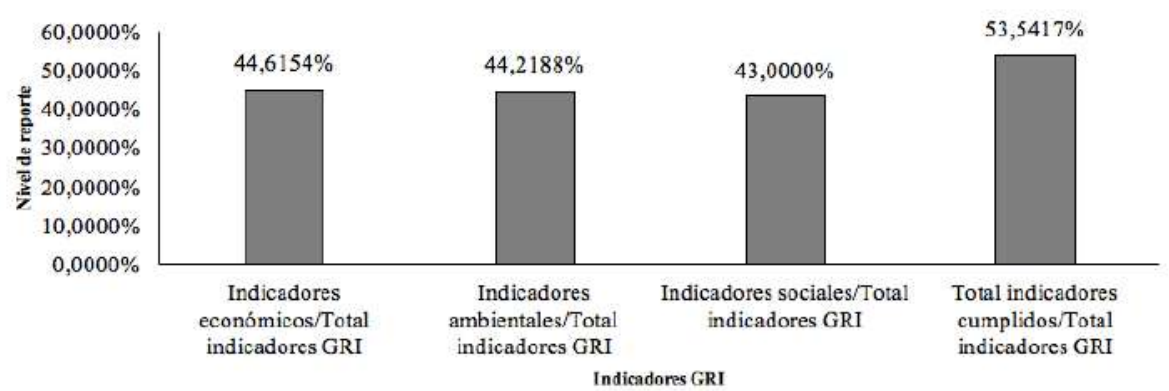

Figura 9. Nivel de reporte del total de las empresas sobre el total de los indicadores Elaboración propia con base en GRI Database. 


\section{Contexto Herrera, J., Ortiz, A., Pacheco, J. y Correa-García, J.}

Por otra parte, de manera general, se expondrá la cantidad de reporte de los indicadores económicos (serie 200) y sociales (serie 400), los cuales servirán de insumo para futuras investigaciones.

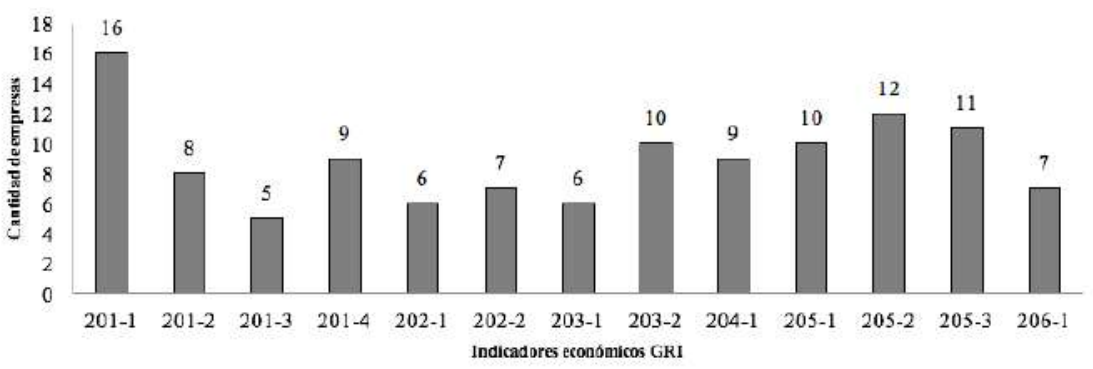

Figura 10. Incidencia indicadores económicos del total de empresas de los países seleccionados ${ }^{3}$ Elaboración propia con base en GRI Database.

En primer lugar, la Figura 10 muestra que los indicadores más importantes revelados por parte de las empresas (aquellos mayores a diez) son: 201-1 valor económico directo generado y distribuido, 205-2 comunicación y formación sobre políticas y procedimientos anticorrupción, 205-3 casos de corrupción confirmados y medidas tomadas. Lo anterior permite pensar que las empresas del sector químico del Área Metropolitana del Valle de Aburrá, también deben estar en las mismas condiciones para reportar esta información, como mínimo.

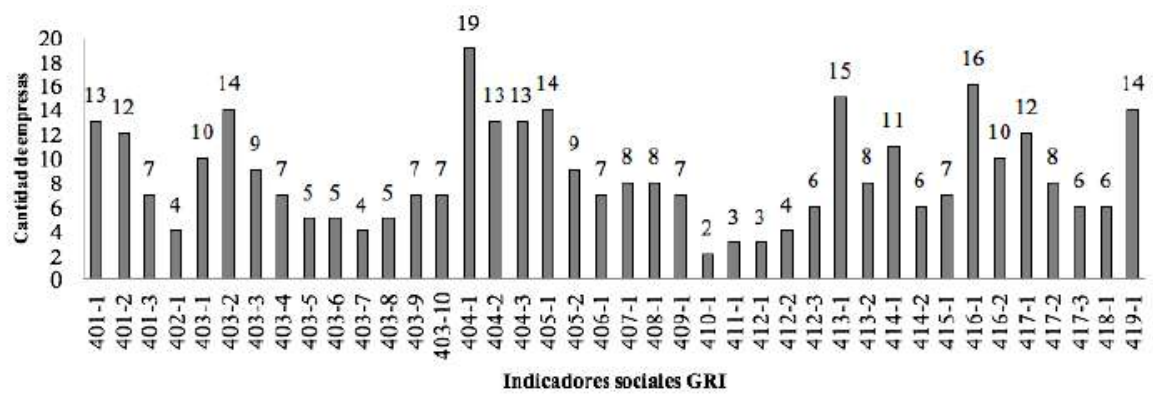

Figura 11. Incidencia de indicadores sociales total empresas de los países seleccionados ${ }^{4}$ Elaboración propia con base al GRI Database.

\footnotetext{
${ }^{3}$ Ver anexo 4. Glosario de indicadores del Global Reporting Initiative, ATKearney, y Liga de directores (2016).

${ }^{4}$ Ver anexo 4. Glosario de indicadores del Global Reporting Initiative, ATKearney, y Liga de directores (2016).
} 
En consecuencia, los indicadores sociales que mayor incidencia en la revelación tuvieron son los mayores a diez, observados en la Figura 11. En este punto, es preciso afirmar que las empresas del sector químico del Área Metropolitana del Valle de Aburrá también estarán en la capacidad de informar acerca de la mayoría de los siguientes indicadores como mínimo: 404-1 media de horas de formación al año por empleado; 416-1 evaluación de los impactos en la salud y seguridad de las categorías de productos o servicios; 413-1 operaciones con participación de la comunidad local, evaluaciones del impacto y programas de desarrollo; 403-2 Identificación de peligros, evaluación de riesgos e investigación de incidentes; 4051 diversidad en órganos de gobierno y empleados; 419-1 incumplimiento de las leyes y normativas en los ámbitos social y económico; 401-1 nuevas contrataciones de empleados y rotación de personal; 404-2 programas para mejorar las aptitudes de los empleados y programas de ayuda a la transición; 404-3 porcentaje de empleados que reciben evaluaciones periódicas del desempeño y desarrollo profesional; 401-2 prestaciones para los empleados a tiempo completo que no se dan a los empleados a tiempo parcial o temporales; 417-1 requerimientos para la información y el etiquetado de productos y servicios; y 414-1 nuevos proveedores que han pasado filtros de selección de acuerdo con los criterios sociales.

\section{Empresas químicas del Área Metropolitana del Valle de Aburrá respecto a indicadores medioambientales}
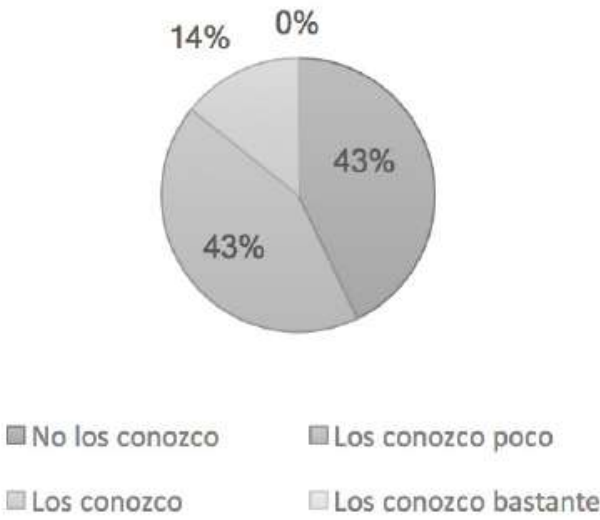

Figura 12. Conocimiento sobre GRI empresas químicas del Área Metropolitana del Valle de Aburrá

Elaboración propia.

A continuación, se realizará el análisis de los indicadores medioambientales en las empresas del sector químico del Área Metropolitana del Valle de Aburrá. Es necesario aclarar que estas empresas son catalogadas como grandes y medianas, 


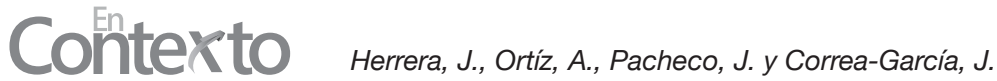

las cuales, a pesar de presentar información sostenible por medio de un informe de sostenibilidad o un capítulo en su informe de gestión, no es desarrollado bajo los estándares establecidos por el GRI. También es importante afirmar que, de la muestra de empresas del sector químico, solo siete de ellas dieron respuesta al instrumento aplicado. No obstante, con los resultados obtenidos se puede evidenciar la clara tendencia que tienen hacia el tratamiento de la información medioambiental.

En primer lugar, es necesario analizar el grado de conocimiento que tienen estas empresas sobre los estándares que emiten. La Figura 12 muestra que el 43\% de estas empresas tienen poco conocimiento o no conocen los estándares GRI. Sin embargo, el 14\% de las empresas encuestadas los conoce, pero no los aplica; esto probablemente se debe a que en la mayoría de ocasiones, en las empresas existe la creencia de que implementar conceptos de sostenibilidad, les generará costos adicionales elevados (Schneider, 2019).

También podría deberse a que la autoridad ambiental del Área Metropolitana del Valle de Aburrá, de acuerdo con la entrevista realizada, solamente exige reportes que sus mismos profesionales proponen; de modo que se evidencie la gestión de los recursos naturales (agua, suelo y aire) cuando la entidad lleve a cabo las visitas de inspección y vigilancia. En pocas palabras, esto apunta a que no existe presión por dicho ente para que las compañías químicas se ajusten a los parámetros GRI en la elaboración de informes de sostenibilidad.

La situación es un poco preocupante, puesto que, en primer lugar, la elaboración y publicación de informes de sostenibilidad es un factor de suma importancia frente a temas de reputación empresarial, y así ganar legitimidad frente a sus stakeholders. De acuerdo con ello, Hart et al. (2003) indican que las empresas deben informar de manera adecuada a los stakeholders, de modo que se establezca un gran vínculo comunicativo entre las partes, permitiendo mejorar la reputación de la organización. Estas deberían considerar que los problemas de sostenibilidad, en relación a la producción, distribución y consumo de bienes y servicios, desafían cada vez más su legitimidad (Scherer et al., 2012).

En otro orden de ideas, por medio de la aplicación del instrumento, se conoció la capacidad que tenían las empresas de revelar información acerca de algunos indicadores medioambientales, los cuales fueron los más importantes de cada grupo de estándares identificados en el benchmarking de las empresas latinoamericanas, tal como se observa en la Figura 13. 


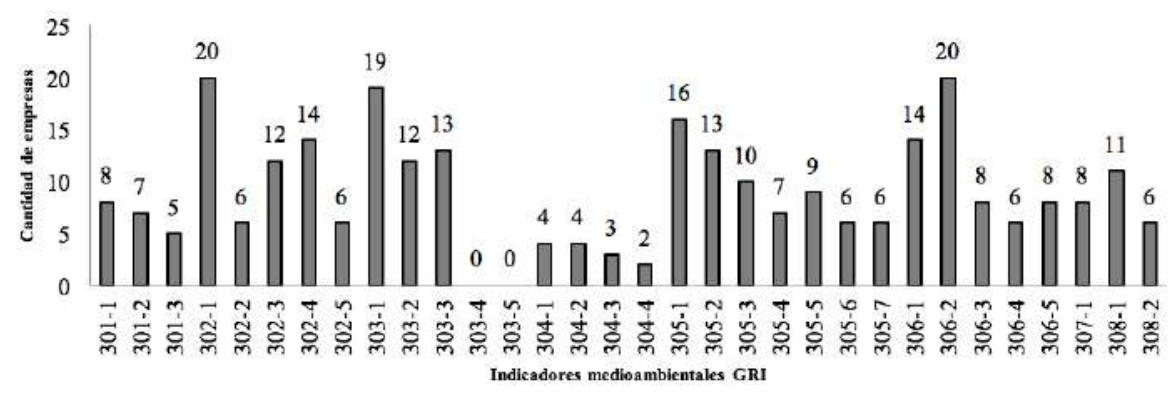

Figura 13. Incidencia indicadores ambientales ${ }^{5}$

Elaboración propia con base en GRI Database.

Es por ello que la Figura 14 muestra los indicadores que tienen mayor facilidad de obtener información y, por ende, se les haría más fácil darla a conocer.

Los resultados de la encuesta muestran que el indicador que sería más factible a revelar por parte de las empresas del sector químico es el 307-1 incumplimiento de la legislación y normativa ambiental, con un 86\% de capacidad para revelar; seguido de los indicadores 302-1 consumo energético dentro de la organización y 303-2 gestión de los impactos relacionados con los vertidos de agua, con 71\%. Por último, con capacidad para revelar de un $57 \%$, se presentan indicadores como el 301-1 materiales utilizados por peso y volumen; 302-1 insumos reciclados; 302-3 intensidad energética; 302-4 reducción del consumo energético; y 305-1 emisiones directas de GEI. Por otro lado, se puede evidenciar que para las empresas es muy poco probable revelar información respecto al indicador 302-2 consumo energético fuera de la organización; y con un 57\% es también improbable que revelen información acerca de biodiversidad y hábitats restaurados, emisiones indirectas de GEI, reducción de emisiones de GEI y evaluación de nuevos proveedores a partir de su política ambiental. Por ello, el Área Metropolitana del Valle de Aburrá lleva a cabo un acompañamiento a las empresas, a través de asesorías, talleres y capacitaciones, orientados al manejo de las sustancias químicas, química verde, eco innovación, entre otros. De modo que las organizaciones químicas lleven a cabo acciones en pro del medio ambiente, y puedan hacer un reporte sostenible de manera que satisfaga las necesidades de los stakeholders.

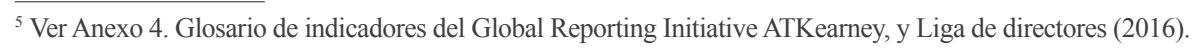




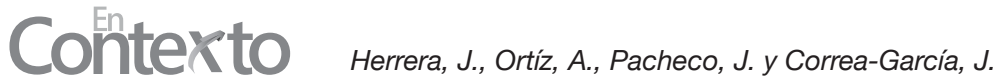

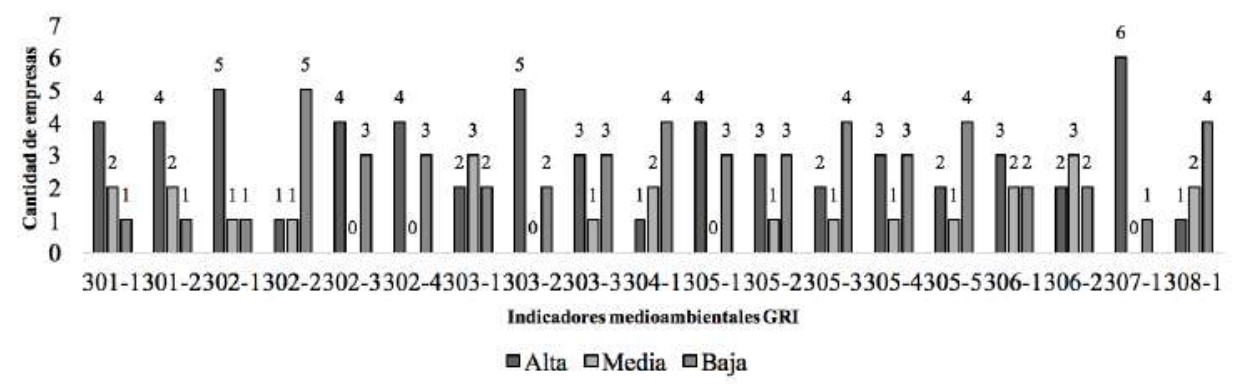

Figura 14. Capacidad de revelar por parte de las empresas ${ }^{6}$

Elaboración propia con base a las encuestas.

\section{Nivel de priorización de ODS en las empresas latinoamericanas}

Los ODS, como base primordial de la agenda 2030 de la ONU, también tienen parte activa dentro de los informes de sostenibilidad, puesto que con la incorporación del SDG Compass se han sumado a los indicadores del GRI para la elaboración de reportes.

Lo anterior, se lleva a cabo agregando una columna al índice de contenido del reporte, para diagramar contenidos del GRI relevantes frente a la lista de ODS priorizados (Bertazzi et al., 2016).

Por medio de este diagrama, el stakeholder conoce los indicadores aplicados por la compañía e identifica por medio de ellos, el objetivo de la agenda 2030, al que apunta la compañía.

De acuerdo con el análisis de los ODS en las memorias de sostenibilidad de los países latinos seleccionados, se obtiene que, de las 20 empresas analizadas para cada uno de los 17 ODS propuestos por la ONU, hay una priorización en mayor medida del ODS5-Igualdad de género, junto con el ODS8-Empleo digno y crecimiento económico y el ODS13-Acción por el clima, tal como se evidencia en la Tabla 3. Sin embargo, el objetivo de desarrollo sostenible con menor nivel de priorización es el número 11, definido como ciudades y comunidades sostenibles.

\footnotetext{
${ }^{6}$ Ver Anexo 4. Glosario de indicadores del Global Reporting Initiative ATKearney, y Liga de directores (2016).
} 
Tabla 3

Nivel de priorización de ODS por parte de las empresas

\begin{tabular}{lcc}
\hline Objetivo de desarrollo sostenible & $\begin{array}{c}\text { Número de } \\
\text { empresas }\end{array}$ & $\begin{array}{c}\text { Participación } \\
\text { relativa }\end{array}$ \\
\hline Erradicación de la pobreza. & 10 & $50,00 \%$ \\
\hline Hambre cero. & 7 & $35,00 \%$ \\
\hline Salud y bienestar. & 11 & $55,00 \%$ \\
\hline Educación de calidad. & 10 & $50,00 \%$ \\
\hline Igualdad de género. & 12 & $60,00 \%$ \\
\hline Agua limpia y saneamiento. & 11 & $55,00 \%$ \\
\hline Energía limpia. & 11 & $55,00 \%$ \\
\hline Empleo digno y crecimiento económico. & 12 & $60,00 \%$ \\
\hline Innovación e infraestructura. & 9 & $45,00 \%$ \\
\hline Reducción de la desigualdad. & 10 & $50,00 \%$ \\
\hline Ciudades y comunidades sostenibles. & 5 & $25,00 \%$ \\
\hline Producción y consumo sostenible. & 11 & $55,00 \%$ \\
\hline Acción por el clima. & 12 & $60,00 \%$ \\
\hline Vida submarina. & 7 & $35,00 \%$ \\
\hline Vida de ecosistemas terrestres. & 8 & $40,00 \%$ \\
\hline Paz, justicia e instituciones sólidas. & 11 & $55,00 \%$ \\
\hline Alianzas para el logro de los objetivos. & 10 & $50,00 \%$ \\
\hline
\end{tabular}

Elaboración propia con base al GRI Database.

De las 20 empresas analizadas, el índice de reporte es positivo, porque la inclusión de los ODS bajo la óptica empresarial es algo reciente, como se había mencionado anteriormente, viene desarrollándose desde el año 2016; además, muchas de las empresas carecen de conocimientos y recursos para poder adaptarlos e incluirlos en el informe de sostenibilidad (Naciones Unidas, 2018). Sin embargo, se espera que, con el tiempo, más organizaciones puedan incorporar lo planteado por los ODS de manera oportuna y precisa.

De acuerdo con los resultados anteriormente presentados, se observa el alto nivel de priorización de los ODS 12 (Producción y consumo sostenible) y 13 (Acción por el clima), con un 55\% y 60\% respectivamente del total de las 20 empresas analizadas en el benchmark; se apoya en la respuesta brindada por el Área Metropolitana del Valle de Aburrá, al evidenciarse que los mencionados anteriormente se encuentran listados dentro de los indicados a priorizar por la entidad rectora. 


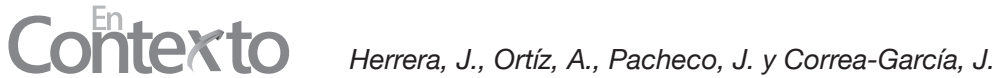

Dentro de los principales, se desarrollan actividades encaminadas a la eficiencia energética a nivel industrial e institucional, el manejo de sustancias químicas y residuos peligrosos, gestión hídrica, compras sostenibles, construcción sostenible, distritos térmicos, económica circular, química verde, y movilidad sostenible con énfasis en tecnologías eléctricas.

\section{Los ODS en las empresas químicas del Área Metropolitana del Valle de Aburrá}

Respecto a los ODS, las empresas del sector químico del Área Metropolitana del Valle de Aburrá mostraron una tendencia que apunta a un bajo grado de conocimiento y entendimiento sobre los ODS. Según se observa en Figura 15, de las empresas encuestadas solo el 14\% de ellas los conocen; el 29\% lo conocen poco, es decir, han escuchado de ellos (el porcentaje apunta a dos empresas); y finalmente, el 57\% no lo conocen, la cual es la respuesta dada por las cuatro empresas restantes.

La razón principal respecto a los resultados arrojados está encaminada a la falta de información, ya que las empresas en su mayoría no priorizan sus actividades con base en los ODS. Es por ello que Vives (2019) afirma que entre más conocidos sean los ODS, más empresas tendrán la posibilidad de tomar acciones en cuanto a ellos; sin embargo, su promoción debe hacerse con efectividad por parte de empresas consultoras, organizaciones de sociedad civil y el mismo gobierno. Por tal motivo, en Antioquia se viene desarrollando el programa Antioquia sostenible, liderado por seis organizaciones, entre las cuales se encuentra la Fundación para el Desarrollo ProAntioquia, que desde 2015 ya ha vinculado a más de 150 entidades en esta iniciativa (Proantioquia, 2016) y se espera que esta llegue al sector químico del Área Metropolitana del Valle de Aburrá pronto.

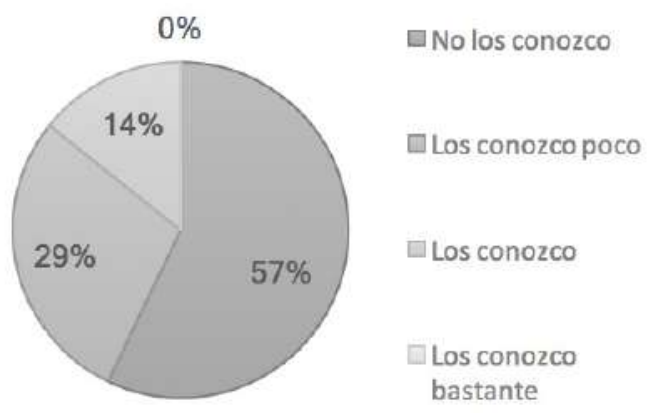

Figura 15. Conocimiento sobre ODS empresas químicas del Área Metropolitana del Valle de Aburrá

Elaboración propia. 


\section{Conclusiones}

En el presente trabajo, se establecieron los indicadores medioambientales que podrían revelar las empresas del sector químico del Área Metropolitana del Valle de Aburrá, a través de encuestas, entrevistas y un benchmarking con empresas latinoamericanas. Los resultados arrojados muestran que las empresas químicas de esta zona geográfica de Antioquia tienen un bajo o nulo conocimiento acerca de la metodología GRI y de los ODS, lo que conlleva a que no se presenten reportes; si se llevan a cabo, no hay una directriz adecuada para elaborarlos, puesto que no existe una presión adecuada para desarrollar informes bajo metodología GRI por parte de la entidad de vigilancia y control del Área Metropolitana del Valle de Aburrá.

Por otro lado, las empresas latinoamericanas evaluadas en el benchmark presentan una alta inclinación en cuanto a los indicadores 302-energía, 303-agua y efluentes, 305-emisiones y 306-efluentes y residuos; lo cual contrasta con lo observado en las respuestas a las encuestas de las empresas químicas del Área Metropolitana del Valle de Aburrá, puesto que estas arrojaron un resultado favorable a los indicadores 302-energía, 303-agua y efluentes y 306-efluentes y residuos. Cabe destacar que las respuestas a la encuesta por parte de las organizaciones fueron una cantidad mínima de la muestra propuesta.

Por otra parte, respecto al benchmark de los ODS, se observó que las compañías que priorizan en mayor medida los ODS5-igualdad de género, ODS8-empleo digno y crecimiento económico y ODS13-acción por el clima, lo cual es totalmente contrario a lo observado en las empresas químicas del Área Metropolitana del Valle de Aburrá, debido que estas, según las encuestas, no priorizan conscientemente ningún objetivo, sumado a que ni siquiera tienen conocimiento de ello. No obstante, de acuerdo con la entrevista realizada al ente de vigilancia y control del Área Metropolitana del Valle de Aburrá se observa que los objetivos que podrían priorizar este tipo de empresas son similares a los arrojados en el benchmark de las empresas latinas.

Con base en lo mencionado, los indicadores GRI en que podrían enfocarse las empresas químicas del Área Metropolitana del Valle de Aburrá a la hora de elaborar un informe de sostenibilidad, de manera que todos sus agentes de interés se vean beneficiados y satisfechos de acuerdo con sus necesidades de información, son los siguientes: 302-Energía, 303-Agua y efluentes, 305-Emisiones y 306-Efluentes y residuos; de manera que prioricen los ODS5-Igualdad de género, ODS8-Empleo digno y crecimiento económico y ODS13-Acción por el clima. 


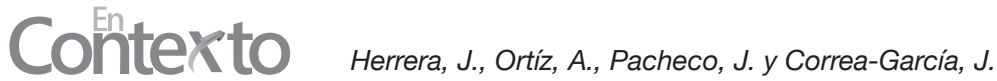

Por otra parte, es preciso que se genere más sensibilización, capacitación y estímulos a las empresas por parte de la entidad de vigilancia y control del Área Metropolitana del Valle de Aburrá. Esto de modo que haya más iniciativa en la preparación de informes de sostenibilidad con contenidos priorizados por parte de las empresas.

Por último, es importante resaltar que este artículo fue realizado con restricciones de información, las cuales se generaron por la escasa respuesta de parte de las empresas encuestadas. No obstante, a través de este se brinda apertura a nuevas exploraciones en temas relacionados de responsabilidad social; y se abre la invitación a que futuras investigaciones profundicen el presente artículo, y lo complementen con los indicadores económicos y sociales en el mismo sector $\mathrm{u}$ otros diferentes, para así continuar contribuyendo con la sostenibilidad del planeta y mejorar la calidad de los informes de sostenibilidad no solo en Colombia, sino en el mundo.

\section{Referencias}

Arias-Alosilla, Y., y Linares-Romero, M. (2008). Desarrollo de un Reporte de Sostenibilidad basado en la Metodología del Global Reporting Initiative (GRI) [Tesis de maestría, Pontificia Universidad Católica del Perú. Repositorio institucional - Pontificia Universidad Católica del Perú.]. http:// tesis.pucp.edu.pe/repositorio/handle/20.500.12404/304

Aristizábal, M. (2018). Análisis de la situación y recomendaciones de política de bioeconomía. 40. https://www.dnp.gov.co/Crecimiento-Verde/ Documents/ejes-tematicos/Bioeconomia/Informe\%202/ANEXO\%203 An\%C3\%A1lisis\%20sector\%20qu\%C3\%ADmico.pdf

Asamblea General de las Naciones Unidas. (2015). Resolución Transformar nuestro mundo: La Agenda 2030 para el Desarrollo Sostenible (Vol. 15900). https://undocs.org/es/A/RES/70/1

Becerra, M., y Espinoza, G. (2002). Gestión ambiental en América Latina y el Caribe. Evolución, tendencias y principales prácticas. Banco Interamericano de Desarrollo y la Organización Panamericana. http://documentacion. ideam.gov.co/openbiblio/bvirtual/019857/GestionambientalenA.L.yelC/ GestionAmb..pdf

Berenguer-Ungaro, M., Rodríguez-Clavijo, Y., Hernández-Rodríguez, N., MoralesPérez, M., y Estrada-Rodríguez, J. (2019). Las funciones de la economía política como guía en el análisis de la gestión energética. Economía y desarrollo, 162(2), 1-10. http://scielo.sld.cu/pdf/eyd/v162n2/0252-8584eyd-162-02-e15.pdf 
Bertazzi, P., Hansen, O., y Didden, M. (2016). La guía para la acción empresarial en los ODS. Pacto Global de las Naciones Unidas. https://www.pactomundial.org/ wp-content/uploads/2016/10/SDG_Compass_Spanish-one-pager-view.pdf

Burhan, A., \& Rahmanti, W. (2012). The impact of sustainability reporting on company performance. Journal of Economics, Business, and Accountancy Ventura, 15(2), 257-272. http://dx.doi.org/10.14414/jebav.v15i2.79

Business Reporting on the SDGs. (2017). An analysis of the goals and targets. https://www.unglobalcompact.org/docs/publications/GRI_UNGC_SDG_ Reporting_An_Analysis_of_Goals_and_Targets_2017.pdf

Colciencias. (2019). Misión internacional de sabios para el avance de la Ciencia, la Tecnología y la Innovación. Pacto por la Ciencia, la Tecnología y la Innovación: Un sistema para construir el conocimiento del futuro. Gobierno de Colombia

Colombia Productiva y PricewaterhouseCoopers. (2019). Sector Químicos-Visión a 2032. https://www.colombiaproductiva.com/ptp-capacita/publicaciones/ sectoriales/publicaciones-quimica-basica/plan-de-negocio-industriaquimica-basica-2019-2032\#: :text=El\%20tama $\% \mathrm{C3} \% \mathrm{~B} 1 \mathrm{o} \% 20 \mathrm{del} \% 20$ sector $\% 20$ de, bioindustriales $\% 20 \mathrm{y} \% 20 \mathrm{de} \% 20 \mathrm{~s} \% \mathrm{C} 3 \%$ ADntesis $\% 20$ qu $\%$ C $3 \%$ ADmica.

Comunicación Activa. (2019). La Comunicación para el Desarrollo, los ODS y los estándares GRI para una sociedad sustentable. http://comunicacionactiva. com.co/comunicacion-desarrollo-sustentable-ods-gri/

Comunidad Andina. (s.f.). Comunidad andina. Somos Comunidad Andina. http:// www.comunidadandina.org/Seccion.aspx?id=189\&tipo=QU\&title=somoscomunidad-andina

De la Cruz-Monte de Oca, F., Furet-Bridón, N., y Turtós-Carbonell, L. (2011). La dispersión atmosférica de contaminantes en una zona industrial de Cuba. Revista CENIC. Ciencias Químicas, 42(2-3), 1-7.

Deegan, C. (2014). Financial Accounting Theory. McGraw-Hill Education.

Díez-Martín, F., Blanco-González, A., y Prado-Román, C. (2010). Legitimidad como factor clave del éxito organizativo. Investigaciones Europeas de Dirección y Economía de la Empresa, 16, 127-143.

Díez-Martín, F., Cruz-Suárez, A., Blanco-González, A., y Prado-Román, C. (2014). Efecto de la Responsabilidad Social Empresarial sobre la Legitimidad de las Empresas. Anuario Jurídico y Económico Escurialense, XLVII, 325348. http://www.rcumariacristina.net:8080/ojs/index.php/AJEE/article/ viewFile/194/163 


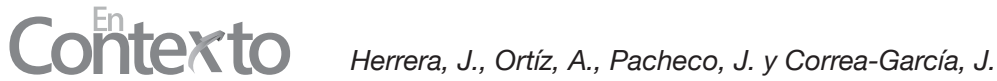

Donaldson, T., \& Preston, L. (1995). The Stakeholder Theory of the Corporation : Concepts, Evidence, and Implications. The Academy of Management, 20(1), 65-91.

Dowling, J., \& Pfeffer, J. (1975). Organizational legitimacy: Social values and organizational behavior. Sociological Perspectives, 18(1), 122-136. https:// doi.org/10.2307/1388226

EFE. (16 de febrero de 2018). Los productos químicos que usas en el día a día contaminan tanto la ciudad como el coche. Público. https://www.publico. es/ciencias/contaminacion-productos-quimicos-dia-dia-contaminan-ciudadcoche.html

Fernández, J., y Bajo, A. (2012). La Teoría del Stakeholder o de los Grupos de Interés. ADResearch, 6(6), 122. https://dialnet.unirioja.es/servlet/ articulo? codigo $=3980299$

Freeman, R. (1984). Strategic Management. Pitman Publishing Inc.

Global Reporting Initiative, ATKearney, y Liga de directores. (2016). Direccionando la sostenibiilidad desde el directorio. El caso latinoamericano. https://cupdf. com/document/direccionando-la-sostenibilidad-desde-el-directorio.html

Global Sustainability Standards Board (GSSB). (2016). GRI 101: Fundamentos 2016 101. GSSB Global Sustainability Standars Board, 1(1), 30.

Gómez-Villegas, M., y Quintanilla, D. (2012). Los informes de responsabilidad social empresarial: su evolución y tendencias en el contexto internacional y colombiano. Cuadernos de Contabilidad, 13(32), 121-158. http://revistas. javeriana.edu.co/index.php/cuacont/article/view/3894

González, E. (2007). La teoría de los "stakeholders". Un puente para el desarrollo práctico de la ética empresarial y de la responsabilidad social corporativa. Veritas: Revista de filosofía y teología, 2(17), 205-224.

Hart, S., Milstein, M., \& Caggiano, J. (2003). Creating sustainable value. Academy of Management Executive, 17(2), 56-69. https://doi.org/10.5465/ ame.2003.10025194

Heredia-Rodríguez, L., y Gómez-Jiménez, J. (2011). Las demandas de los stakeholders y la evolución de las memorias de sostenibilidad del GRI: un análisis desde la transparencia y la creación de valor. Economía Gestión y Desarrollo, 10, 11-36.

Husillos-Carqués, F. (2007). Una aproximación desde la teoría de la legitimidad a la información medioambiental revelada por las empresas españolas cotizadas. Revista Española de Financiación y Contabilidad, 36(133), 97-121. 
Jones, T. (1995). Instrumental stakeholder theory: A synthesis of ethics and economics. The Academy of Management, 20(2), 404-437. https://www. jstor.org/stable/258852? seq $=1$

Ley 905 de 2004. Por medio de la cual se modifica la Ley 590 de 2000 sobre promoción del desarrollo de la micro, pequeña y mediana empresa colombiana y se dictan otras disposiciones., Diario Oficial No. 45.628 de 2 de agosto de 2004.

Lock, I., \& Seele, P. (2015). Analyzing sector-specific CSR reporting: Social and environmental disclosure to investors in the chemicals and banking and insurance industry. Corporate Social Responsibility and Environmental Management, 22(2), 113-128. https://doi.org/10.1002/csr.1338

Marciales, L. (08 de noviembre de 2018). La Red de Pacto Global tiene más de 590 organizaciones adheridas en Colombia. La república. https://www. larepublica.co/responsabilidad-social/la-fundacion-red-de-pacto-global-decolombia-tiene-597-organizaciones-adheridas-2791353

Montes-Valencia, N. (2015). La Industria Química: Importancia y Retos. Lámpsakos, 14, 72-85. https://doi.org/10.21501/21454086.1562

Naciones Unidas. (2018). Informe de los Objetivos de Desarrollo Sostenible 2018. En Naciones Unidas. https://doi.org/10.18356/94620aa1-es

ONU Noticias. (16 de mayo de 2019). Fiji se enfrentó a los escépticos y negacionistas y el mundo está escuchando. ONU Noticias. https://news. un.org/es/story/2019/05/1456081

Pacto Global Red Colombia. (2018). Informe de gestión 2018. Corporación red local del pacto global en Colombia. https://www.pactoglobal-colombia.org/images/ PDFs/RTE/Informe_de_Gestion_2018_Pacto_Global_definitivo.pdf

Palacios, C., y Coppa, C. (2015). Informe de sostenibilidad. Criterios y procedimientos en el mapeo de stakeholders. Un estudio de caso. Cuadernos de Contabilidad, 16(40), 233-259. https://doi.org/10.11144/javeriana.cc16-40.iscp

Proantioquia. (2016). Los ODS y su apropiación en el territorio. https://www. proantioquia.org.co/node/24753

Programa de las Naciones Unidas para el Desarrollo (PNUD). (2015). The global goals- For sustainable development. The global goals. https://www. globalgoals.org/

Programa de las Naciones Unidas para el Desarrollo (PNUD). (2019). Objetivos de Desarrollo Sostenible. https://www.undp.org/content/undp/es/home/ sustainable-development-goals.html 


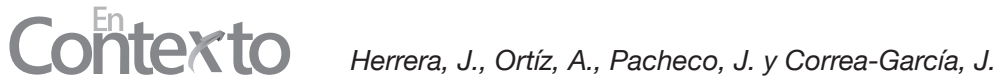

Rodríguez-Guerra, L., y Ríos-Osorio, L. (2016). Evaluación de sostenibilidad con Metodología GRI. Dimensión Empresarial, 14(2), 73-89. https://doi. org/10.15665/rde.v14i2.659

Scherer, A., Palazzo, G., \& Seidl, D. (2012). Managing Legitimacy in Complex and Heterogeneous Environments: Sustainable Development in a Globalized World. SSRN Electronic Journal. University of Zurich, 306, 1-50. https:// doi.org/10.2139/ssrn.2137060

Schneider, H. (2019). Guía para integrar la sostenibilidad en las empresas. ResCA-Fundemas. http://www.resilientcentralamerica.org/wp-content/ uploads/2019/Guía/ResCA-GuíaSustentabilidadEmpresas-FINAL.pdf

Scott, W., Ruef, M., Mendel, P., y Caronna, C. (2000). Institutional change and healthcare organizations. The university of Chicago.

Suchman, M. (1995). Managing Legitimacy: Strategic and Institutional Approaches. Academy of Management Review, 20(3), 571-610. https://www.jstor.org/ stable $/ 258788$ ?seq $=1$

Vaca-Acosta, R., Moreno-Domínguez, M., y Riquel-Ligero, F. (2007). Análisis de la responsabilidad social corporativa desde tres enfoques: stakeholders, capital intelectual y teoría institucional. Conocimiento, innovación $y$ emprendedores: Camino Al Futuro, 3130-3143.

Vives, A. (2013). Mirada Crítica a la Responsabilidad Social de la Empresa en Iberoamérica. (Volumen 2). Cumpetere.

Vives, A. (2019). Mirada Crítica a la Responsabilidad Social de la Empresa en Iberoamérica. (Volumen 5). Cumpetere.

Weber, M. (1964). Economía y Sociedad. (2 ed.). Fondo de cultura económica.

Wicks, A., Gilbert, D., \& Freeman, R. (1994). A Feminist Reinterpretation of The Stakeholder Concept. Business Ethics Quarterly, 4(4), 475-497. https://doi. org $/ 10.2307 / 3857345$

\section{Para citar este artículo:}

Herrera, J., Ortíz, A., Pacheco, J. y Correa-García, J. (2021). Indicadores medioambientales y Objetivos de Desarrollo Sostenible (ODS) a revelar por parte de empresas del sector químico. En-Contexto, $9(14), 151-184$. 


\title{
Anexo 1. Encuesta
}

\author{
UNIVERSIDAD DE ANTIOQUIA \\ FACULTAD DE CIENCIAS ECONÓMICAS \\ DEPARTAMENTO DE CIENCIAS CONTABLES
}

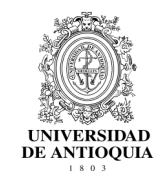

\section{Encuesta dirigida a personal de las compañías}

Pacto de confidencialidad: la siguiente encuesta es realizada por estudiantes de Contaduría Pública de la Universidad de Antioquia con el fin de recolectar información para la investigación denominada indicadores medioambientales a revelar por parte de las empresas químicas del Área metropolitana del Valle de Aburrá. Los resultados obtenidos en esta serán confidenciales y sus fines serán académicos.

\section{Las preguntas marcadas con asterisco son de obligatoria respuesta}

1. Caracterización general de la empresa*

Nombre completo de la empresa
A) Valor de los activos 31 de diciembre a 2018
B) Número de personas que hacen parte de la compañía(empleados)
C) Especifiquelaactividadprincipaldela empresa
D) Domicilio (Municipio)

2. Especifique el tipo de relación con la compañía*
A) Directivo
B) Empleado
C) Otro

A continuación, se mencionan varios informes contables y no contables. Responda afirmativamente, si la compañía emitió información asociada al reporte descrito el año inmediatamente anterior; o negativamente si la compañía no reportó información en dicho año.

3. ¿Qué reporta la empresa?*

\begin{tabular}{lll}
\hline \multicolumn{1}{c}{ Informe Contable } & Sí & No \\
\hline Estado de situación financiera & $\mathrm{O}$ & $\mathrm{O}$ \\
\hline Estado de resultados integral & $\mathrm{O}$ & $\mathrm{O}$ \\
\hline Estado de cambios en el patrimonio & $\mathrm{O}$ & $\mathrm{O}$ \\
\hline
\end{tabular}




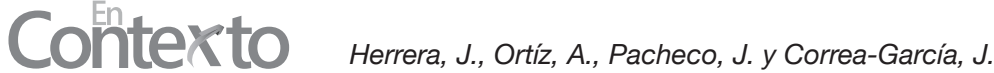

\begin{tabular}{lll}
\hline Estado de flujos de efectivo & $\mathrm{O}$ & $\mathrm{O}$ \\
\hline Notas a los estados financieros & $\mathrm{O}$ & $\mathrm{O}$ \\
\hline Informe de gestión & $\mathrm{O}$ & $\mathrm{O}$ \\
\hline Capítulo de información sostenible en el informe de gestión & $\mathrm{O}$ & $\mathrm{O}$ \\
\hline Informe de sostenibilidad & $\mathrm{O}$ & $\mathrm{O}$ \\
\hline
\end{tabular}

Elaboración propia.

Si la respuesta fue afirmativa en el numeral de "Informe de sostenibilidad" indique sobre qué aspecto reveló la compañía:

\begin{tabular}{llll}
\hline & Tipo de información & Sí & No \\
\hline Ambiental & $\mathrm{O}$ & $\mathrm{O}$ \\
\hline Social & $\mathrm{O}$ & $\mathrm{O}$ \\
\hline Económico & $\mathrm{O}$ & $\mathrm{O}$ \\
\hline
\end{tabular}

Elaboración propia.

\section{De acuerdo con el siguiente párrafo, responda las siguientes preguntas}

"Los Objetivos de Desarrollo Sostenible (ODS), también conocidos como Objetivos Mundiales, son un llamado universal a la adopción de medidas para poner fin a la pobreza, proteger el planeta y garantizar que todas las personas gocen de paz y prosperidad" (Programa de Naciones Unidas para el desarrollo, 2019).

4. ¿Cuál es su grado de conocimiento sobre los ODS? *

O No los conozco.

O Los conozco poco.

O Los conozco.

O Los conozco bastante.

5. Tiene conocimiento si la empresa ha priorizado sus operaciones en virtud de cumplir con los ODS? * Sí No

6. ¿Cuáles?

O Fin de la pobreza.

O Hambre cero.

O Salud y bienestar.

O Igualdad de género. 
O Agua limpia y saneamiento.

O Energía asequible y no contaminante.

O Trabajo decente y crecimiento económico.

O Industria, innovación e infraestructura.

O Reducción de las desigualdades.

O Ciudades y comunidades sostenibles.

O Producción y consumo responsables.

O Acción por el clima.

O Vida submarina.

O Vida de ecosistemas terrestres.

O Paz, justicia e instituciones sólidas.

O Alianza para lograr los objetivos.

\section{De acuerdo con el siguiente párrafo, responda las siguientes preguntas}

"GRI ayuda a las empresas y gobiernos de todo el mundo a comprender y comunicar su impacto en cuestiones críticas de sostenibilidad, como el cambio climático, los derechos humanos, la gobernanza y el bienestar social. Esto permite una acción real para crear beneficios sociales, ambientales y económicos para todos. Los Estándares de Informes de Sostenibilidad GRI se desarrollan con verdaderas contribuciones de múltiples partes interesadas y se basan en el interés público" (Global Reporting Initiative, ATKearney, y Liga de directores 2016).

7. ¿Cuál es su grado de conocimiento sobre el GRI? *

O No los conozco.

O Los conozco poco.

O Los conozco.

O Los conozco bastante.

8. ¿Tiene conocimiento si la empresa ha priorizado sus operaciones en virtud de realizar un informe bajo el marco del GRI? * Sí No

9. ¿Por qué?

10. ¿Qué capacidad tiene la compañía para revelar la siguiente información?*

\begin{tabular}{lccc}
\hline \multicolumn{1}{c}{ ITEM } & Baja & Media & Alta \\
\hline Materiales utilizados por peso y volumen. & $\mathrm{O}$ & $\mathrm{O}$ & $\mathrm{O}$ \\
\hline Insumos reciclados y productos reutilizados. & $\mathrm{O}$ & $\mathrm{O}$ & $\mathrm{O}$ \\
\hline
\end{tabular}




\section{Contexto Herrera, J., Ortíz, A., Pacheco, J. y Correa-García, J.}

\begin{tabular}{lccc}
\hline \multicolumn{1}{c}{ ITEM } & Baja & Media & Alta \\
\hline Consumo energético dentro de la organización. & $\mathrm{O}$ & $\mathrm{O}$ & $\mathrm{O}$ \\
\hline Consumo energético fuera de la organización. & $\mathrm{O}$ & $\mathrm{O}$ & $\mathrm{O}$ \\
\hline Intensidad energética. & $\mathrm{O}$ & $\mathrm{O}$ & $\mathrm{O}$ \\
\hline Reducción del consumo energético. & $\mathrm{O}$ & $\mathrm{O}$ & $\mathrm{O}$ \\
\hline Interacción con el agua como recurso compartido. & $\mathrm{O}$ & $\mathrm{O}$ & $\mathrm{O}$ \\
\hline Gestión de los impactos relacionados con vertidos de agua. & $\mathrm{O}$ & $\mathrm{O}$ & $\mathrm{O}$ \\
\hline Extracción de agua. & $\mathrm{O}$ & $\mathrm{O}$ & $\mathrm{O}$ \\
\hline Biodiversidad, y hábitats restaurados. & $\mathrm{O}$ & $\mathrm{O}$ & $\mathrm{O}$ \\
\hline Emisiones directas de Gases Efecto Invernadero. & $\mathrm{O}$ & $\mathrm{O}$ & $\mathrm{O}$ \\
\hline Emisiones indirectas de Gases Efecto Invernadero al generar energía. & $\mathrm{O}$ & $\mathrm{O}$ & $\mathrm{O}$ \\
\hline Otras emisiones indirectas de Gases Efecto Invernadero. & $\mathrm{O}$ & $\mathrm{O}$ & $\mathrm{O}$ \\
\hline Intensidad de las emisiones de Gases Efecto Invernadero. & $\mathrm{O}$ & $\mathrm{O}$ & $\mathrm{O}$ \\
\hline Reducción de las emisiones de Gases Efecto Invernadero. & $\mathrm{O}$ & $\mathrm{O}$ & $\mathrm{O}$ \\
\hline Vertido de aguas en función de su calidady destino. & $\mathrm{O}$ & $\mathrm{O}$ & $\mathrm{O}$ \\
\hline Residuos por tipo y método de eliminación. & $\mathrm{O}$ & $\mathrm{O}$ & $\mathrm{O}$ \\
\hline Normativa Ambiental. & $\mathrm{O}$ & $\mathrm{O}$ & $\mathrm{O}$ \\
\hline $\begin{array}{l}\text { Nuevos proveedores que han sido evaluados y filtrados de acuerdo } \\
\text { con los criterios ambientales. }\end{array}$ & $\mathrm{O}$ & $\mathrm{O}$ & $\mathrm{O}$ \\
\hline
\end{tabular}

Elaboración propia.

\section{De acuerdo con el siguiente texto, responda la siguiente pregunta}

En el año 2018 se introdujo la ley 1901, cuyo tema fundamental se fundamenta en las BIC (Sociedades comerciales de beneficio e interés colectivo). Estas últimas son "aquellas compañias que sean constituidas de conformidad con la legislación vigente para tales efectos, las cuales, además del beneficio e interés de sus accionistas, actuarán en procura del interés de la colectividad y del medio ambiente. La adopción de la denominación BIC no implica, de ninguna forma, un cambio de tipo societario, o creación de tipo societario nuevo" (Ley 1901 de 2018, art. 2).

"Las BIC tendrán las mismas obligaciones tributarias, pero en su objeto social deberán incluir las actividades de beneficio e interés colectivo que pretendan fomentar; de igual manera, para adoptar esta condición o para darla por terminada, se requerirá una modificación estatutaria; algunas de las características principales de las BIC son las siguientes: 
- Remuneración salarial razonable para sus trabajadores.

- Subsidios para capacitar y desarrollar profesionalmente a sus trabajadores.

- Prácticas de comercio justo.

- Divulgación de EEFF a sus trabajadores.

- Sistemas de iluminación energéticamente eficientes e incentivos a trabajadores por utilizar transporte sostenible.

- Auditorías ambientales sobre eficiencia del uso de los recursos.

- "Manual para sus empleados, entre otras" (Ley 1901 de 2018, parágrafo artículo 2).

11. Con base a ello, ¿Estaría dispuesto a reportar información en el marco de la ley 1901 de $2018 ?$

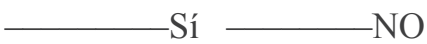

Finalmente, si se desea acceder a los resultados del análisis de ésta, por favor responda lo siguiente:

O. Deseo recibir los resultados y análisis de la investigación.

O. No deseo recibir información acerca de los resultados y análisis de la investigación.

\section{Anexo 2. Empresas en relación a los indicadores}

\begin{tabular}{|c|c|c|c|c|c|c|c|c|c|c|}
\hline \multirow{2}{*}{$\begin{array}{l}\text { Índice por grupos } \\
\qquad G R I \\
\text { Empresa }\end{array}$} & \multicolumn{10}{|c|}{ Brasil } \\
\hline & $\begin{array}{l}\text { Quimi- } \\
\text { cryl }\end{array}$ & Iharabras & $\begin{array}{l}\text { Oxite- } \\
\text { no }\end{array}$ & Eurofarma & $\begin{array}{l}\text { Aché } \\
\text { Labora- } \\
\text { torios }\end{array}$ & Cosmotec & $\begin{array}{c}\text { Dow } \\
\text { Brasil }\end{array}$ & $\begin{array}{c}\text { Daiichi } \\
\text { Sankyo } \\
\text { Brasil }\end{array}$ & $\begin{array}{l}\text { Roche } \\
\text { Brasil }\end{array}$ & $\begin{array}{l}\text { Sanofi } \\
\text { Brasil }\end{array}$ \\
\hline $\begin{array}{l}\text { Generalidades/ } \\
\text { Total indicadores } \\
\text { GRI }\end{array}$ & $57,6 \%$ & $62,7 \%$ & $64,4 \%$ & $67,8 \%$ & $61,0 \%$ & $59,3 \%$ & $61,0 \%$ & $67,8 \%$ & $61,0 \%$ & $61,0 \%$ \\
\hline $\begin{array}{l}\text { Indicadores } \\
\text { económicos/Total } \\
\text { indicadores GRI }\end{array}$ & $15,4 \%$ & $38,5 \%$ & $53,8 \%$ & $30,8 \%$ & $23,1 \%$ & $23,1 \%$ & $23,1 \%$ & $38,5 \%$ & $30,8 \%$ & $15,4 \%$ \\
\hline $\begin{array}{l}\text { Indicadores } \\
\text { ambientales/Total } \\
\text { indicadores GRI }\end{array}$ & $34,4 \%$ & $34,4 \%$ & $43,8 \%$ & $31,3 \%$ & $18,8 \%$ & $25,0 \%$ & $37,5 \%$ & $37,5 \%$ & $15,6 \%$ & $37,5 \%$ \\
\hline $\begin{array}{l}\text { Indicadores } \\
\text { sociales/Total } \\
\text { indicadores GRI }\end{array}$ & $15,0 \%$ & $32,5 \%$ & $55,0 \%$ & $27,5 \%$ & $5,0 \%$ & $27,5 \%$ & $32,5 \%$ & $17,5 \%$ & $17,5 \%$ & $20,0 \%$ \\
\hline $\begin{array}{l}\text { Total indicadores } \\
\text { cumplidos/Total } \\
\text { indicadores GRI }\end{array}$ & $36,8 \%$ & $45,8 \%$ & $56,3 \%$ & $45,1 \%$ & $32,6 \%$ & $39,6 \%$ & $44,4 \%$ & $44,4 \%$ & $36,1 \%$ & $40,3 \%$ \\
\hline
\end{tabular}

Elaboración propia. 
Colitexto ……

\begin{tabular}{lcccc}
\hline \multicolumn{1}{c}{ Índice por grupos GRI } & \multicolumn{4}{c}{ México } \\
\hline Empresa & Liomont & $\begin{array}{c}\text { Petrote- } \\
\text { mex }\end{array}$ & $\begin{array}{c}\text { Pfzer } \\
\text { México }\end{array}$ & $\begin{array}{c}\text { Praxair } \\
\text { México }\end{array}$ \\
\hline Generalidades/ Total indicadores GRI & $62,7 \%$ & $62,7 \%$ & $71,2 \%$ & $61,0 \%$ \\
\hline $\begin{array}{l}\text { Indicadores económicos/Total } \\
\text { indicadores GRI }\end{array}$ & $38,5 \%$ & $76,9 \%$ & $69,2 \%$ & $53,8 \%$ \\
\hline $\begin{array}{l}\text { Indicadores ambientales/Total } \\
\text { indicadores GRI }\end{array}$ & $34,4 \%$ & $81,3 \%$ & $40,6 \%$ & $50,0 \%$ \\
\hline Indicadores sociales/Total indicadores GRI & $25,0 \%$ & $80,0 \%$ & $90,0 \%$ & $32,5 \%$ \\
\hline $\begin{array}{l}\text { Total indicadores cumplidos/Total } \\
\text { indicadores GRI }\end{array}$ & $43,8 \%$ & $72,9 \%$ & $69,4 \%$ & $50,0 \%$ \\
\hline
\end{tabular}

Elaboración propia.

\begin{tabular}{|c|c|c|c|}
\hline Índice por grupos GRI & & Argentina & \\
\hline Empresa & Dow Argentina & Profertil & Savant \\
\hline Generalidades/Total indicadores GRI & $72,9 \%$ & $86,4 \%$ & $62,7 \%$ \\
\hline $\begin{array}{l}\text { Indicadores económicos/Total } \\
\text { indicadores GRI }\end{array}$ & $23,1 \%$ & $46,2 \%$ & $92,3 \%$ \\
\hline $\begin{array}{l}\text { Indicadores ambientales/Total } \\
\text { indicadores GRI }\end{array}$ & $68,8 \%$ & $53,1 \%$ & $62,5 \%$ \\
\hline $\begin{array}{l}\text { Indicadores sociales/Total } \\
\text { indicadores GRI }\end{array}$ & $50,0 \%$ & $40,0 \%$ & $70,0 \%$ \\
\hline $\begin{array}{l}\text { Total indicadores cumplidos/Total } \\
\text { indicadores GRI }\end{array}$ & $61,1 \%$ & $62,5 \%$ & $67,4 \%$ \\
\hline
\end{tabular}

Elaboración propia.

\begin{tabular}{lccc}
\hline \multicolumn{1}{c}{ Índice por grupos GRI } & \multicolumn{3}{c}{ Colombia y Ecuador } \\
\hline \multicolumn{1}{c}{ Empresa } & ANTEK & $\begin{array}{c}\text { Roche } \\
\text { Colombia }\end{array}$ & $\begin{array}{c}\text { Yanbal } \\
\text { Ecuador }\end{array}$ \\
\hline Generalidades/ Total indicadores GRI & $96,6 \%$ & $64,4 \%$ & $89,8 \%$ \\
\hline $\begin{array}{l}\text { Indicadores económicos/Total } \\
\text { indicadores GRI }\end{array}$ & $100,0 \%$ & $15,4 \%$ & $84,6 \%$ \\
\hline $\begin{array}{l}\text { Indicadores ambientales/Total } \\
\text { indicadores GRI }\end{array}$ & $71,9 \%$ & $25,0 \%$ & $81,3 \%$ \\
\hline $\begin{array}{l}\text { Indicadores sociales/Total } \\
\text { indicadores GRI }\end{array}$ & $80,0 \%$ & $45,0 \%$ & $97,5 \%$ \\
\hline $\begin{array}{l}\text { Total indicadores cumplidos/Total } \\
\text { indicadores GRI }\end{array}$ & $86,8 \%$ & $45,8 \%$ & $89,6 \%$ \\
\hline
\end{tabular}

Elaboración propia. 


\section{Anexo 3. Entrevista semiestructurada realizada al Área Metropolitana}

\section{Respuestas a Entrevista semiestructurada \\ Universidad de Antioquia \\ Facultad de Ciencias Económicas \\ Departamento de Ciencias Contables}

1. ¿Qué actividades o programas está realizando el Área Metropolitana del Valle de Aburrá con respecto al reporte de los ODS y protección ambiental por parte de las empresas?

El Área Metropolitana del Valle de Aburrá está conformada por diez municipios: Barbosa, Girardota, Copacabana, Bello, Medellín, Itagüí, Caldas, Sabaneta, Envigado y La Estrella. Es una Entidad administrativa de carácter especial, dotada con personería jurídica, autonomía administrativa, y patrimonio propio creada con el compromiso de consolidar el progreso y el desarrollo armónico de la Gran Región Metropolitana; es autoridad ambiental y de transporte de mediana capacidad, además de ente planificador del territorio con funciones establecidas en la Constitución Política, en la Ley 1625 de 2013, en la Ley 99 de 1993, y demás normas complementarias que rigen las Áreas Metropolitanas.

La Entidad dispone de un Plan Integral de Desarrollo Metropolitano, el Proyecto Metrópoli 2008 - 2020, el cual marca su rumbo y orienta la consolidación de las estrategias definidas en el mismo como Plan Integral de Desarrollo Metropolitano. Plantea como visión al 2020 el establecimiento de una región articulada, con oportunidades de desarrollo sostenible para todos sus habitantes, altos niveles de calidad de vida, con una ciudadanía responsable y participativa que cree y confía en sus instituciones.

De esta manera, uno de los temas fundamentales y estratégicos para el Área Metropolitana del Valle de Aburrá consiste en establecer una rigurosa conceptualización y análisis sobre la sostenibilidad ambiental y territorial, con el fin de identificar las estrategias y acciones más apropiadas y eficientes a implementar por parte de esta Entidad.

La sostenibilidad del territorio implica necesariamente la consideración de múltiples aspectos, como la estructura físico-espacial, la movilidad, los recursos naturales y el ambiente, el equipamiento urbano, el clima y los eventos extremos, la vivienda y 


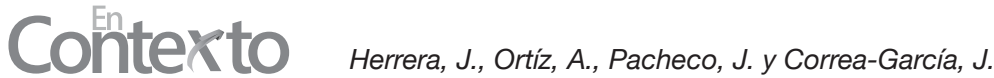

el hábitat, la provisión de servicios públicos, el aseguramiento de la calidad de vida y la inclusión social, entre otros.

En el Plan de Gestión 2016-2019 “Territorios Integrados", se describen de manera general las actividades o programas que está realizando la Entidad respecto al cumplimiento de los Objetivos de Desarrollo Sostenible (ODS) y protección ambiental.

Puntualmente, desde la Unidad de Gestión ambiental se tiene un grupo denominado Producción y Consumo Sostenible, éste desde el 2016 enmarca todas sus acciones en pro del cumplimiento de lo propuesto en los ODS, haciendo especial énfasis en los objetivos 9. Industria, innovación e infraestructura. 11. Ciudades y comunidades sostenibles. 12. Producción y Consumo Responsable. 13. Acción por el clima. 17. Alianzas para lograr los objetivos.

Dentro de las temáticas trabajadas se tienen temas como:

- Eficiencia energética a nivel industrial e institucional.

- Manejo de sustancias químicas y residuos peligrosos.

- Gestión hídrica.

- Compras sostenibles.

- Construcción sostenible.

- Distritos térmicos.

- Económica circular.

- Química verde.

- Movilidad sostenible con énfasis en tecnologías eléctricas.

Ejemplo de lo anterior fue el desarrollo en el 2017 de un proyecto cuyo objeto era el "Fortalecimiento y seguimiento de los Programas de Producción y Consumo Sostenible en el Valle de Aburrá y su área de influencia", mediante el acompañamiento y asistencia técnica en 3 temáticas principales a saber; Eficiencia Energética; Uso Eficiente y Racional del Agua y Gestión de Sustancias Químicas, buscando de esta manera influenciar en la generación de estrategias empresariales que contribuyan al fortalecimiento de la productividad, la competitividad y la Gestión Ambiental.

Respecto a la Unidad de Gestión del riesgo, otro de los grupos de la Subdirección Ambiental, se realizan visitas a las empresas que manipulan, almacenan, transportan, transforman y/o producen sustancias químicas peligrosas (SQP), con el objetivo de fomentar en éstas la adecuada gestión de las SQP en pro de la preservación de los recursos naturales (suelo, agua, aire) y la gestión integral del riesgo de desastres. 
2. ¿Qué información ambiental o sobre los ODS se les solicita a las empresas del sector químico? ¿Cada cuánto lo hacen? ¿Qué hacen con esta información?

Al interior de la Entidad se manejan algunos registros propios o de otras instituciones como el IDEAM. Entre estos se tiene el Inventario de transporte de carga, Departamentos de Gestión Ambiental (DGA), Indicadores de desempeño empresarial, Registro Único Ambiental manufacturero (RUA), Registro de Generadores de Residuos Peligrosos (RESPEL), entre Otros.

Adicionalmente, dentro del Programa de Reconocimiento Empresarial en Sostenibilidad (donde pueden participar de forma voluntaria todas las empresas ubicadas en la zona urbana del Valle de Aburrá, incluidas las del sector químico), se le solicita a las empresas la información asociada al cumplimiento de los ODS lo anterior para poder establecer un criterio diferenciador que permita evaluar el estado de su complimiento apoyado en una metodología que incluya indicadores que midan el aporte a los ODS.

En cuanto a la información ambiental, el Área Metropolitana como autoridad ambiental, durante las visitas de inspección, vigilancia y control solicita información relacionada con el uso adecuado de los recursos naturales por parte de las empresas (agua, suelo, aire), verificando que siempre se encuentren cumpliendo lo establecido en la normatividad colombiana. Se procura realizar seguimiento a las empresas una vez al año.

3. ¿Cuáles objetivos de desarrollo sostenible considera que deben priorizar más entidades del sector químico del Área metropolitana del Valle de Aburrá?

La Agenda 2030 para el Desarrollo Sostenible, que engloba los 17 Objetivos de Desarrollo Sostenible (ODS), presenta grandes retos que exigen la unión de soluciones políticas, económicas, ambientales, sociales, científicas y tecnológicas. A través de la gestión responsable de los productos químicos, el sector químico puede apoyar a los ODS, con productos y prácticas innovadoras que protejan el medio ambiente, minimicen los impactos negativos y promuevan el progreso social. Por lo anterior, consideramos importante que se enfoquen principalmente en los ODS 9. Industria, innovación e infraestructura. 12. Producción y Consumo Responsable. 13. Acción por el clima. 17. Alianzas para lograr los objetivos.

4. ¿Qué necesidades y limitaciones identifica en las entidades del sector químico para que éstas revelen información ambiental o de ODS? 


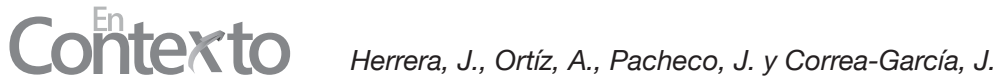

Las limitaciones identificadas pueden estar relacionadas con la entrega de información confidencial de un producto químico.

5. ¿Qué tipo de actividades o capacitaciones se llevan a cabo para que las empresas mejoren sus prácticas ambientales como lo es lo referente al adecuado manejo de las sustancias químicas?

Dentro de los diferentes convenios y acuerdos ejecutados en la Entidad bajo la supervisión del grupo de Producción y Consumo Sostenible, en los últimos años se han fortalecido a más de 365 empresas en temas asociados a gestión de sustancias químicas y RESPEL, lo anterior a través de asesorías con profesionales expertos en las temáticas mencionadas. Adicional, se han realizado talleres y capacitaciones en temas de química verde, eco innovación, económica circular, manejo de sustancias químicas, sistema globalmente armonizado, entre otros.

Desde la Unidad de Gestión del Riesgo, se realizan visitas de inspección a empresas que manipulen sustancias químicas peligrosas - SQP, donde se verifica tanto las características en el almacenamiento como en la manipulación de las sustancias y se realizan requerimientos y recomendaciones a dichas empresas, lo anterior para promover su adecuada gestión. También se realizan visitas del Mapa de Riesgo Químico - MRQ, a empresas de los 10 municipios del Valle de Aburrá (que pueden estar dentro o por fuera de nuestra jurisdicción). En estas visitas se recopila información necesaria para la actualización de dicho mapa, lo que permite generar una calificación cualitativa de los peligros asociados al uso de sustancias químicas peligrosas.

El aplicativo Mapa de riesgo químico - MRQ permite sistematizar, clasificar y visualizar actividades industriales fijas donde se tiene presencia de sustancias químicas peligrosas, a través de un análisis preliminar de peligros, planteando la evaluación de cuatro (4) elementos principales agrupados en cuatro módulos:

1. Nivel de peligro asociado a sustancias, procesos y servicios: en este módulo se identifica y clasifica los peligros que se pueden encontrar en una instalación que maneja sustancias químicas peligrosas y ciertos procesos y servicios.

2. Distancias de protección y aislamiento de la Guía de Respuesta a Emergencias (GRE): en este módulo se determinan las distancias para la atención de emergencias recomendadas por la GRE, por posibles afectaciones a personas, medio ambiente e infraestructura y su relación con la presencia de sustancia en la instalación. 
3. Controles administrativos: en este módulo se identifica cuáles son los controles que implementa la empresa para gestionar sus riesgos, es decir cuáles son las brechas que tiene el sistema de gestión para enfrentarse a los peligrosos por la presencia de sustancias químicas peligrosas.

4. Controles de ingeniería: aquí se identifican cuáles son los controles de ingeniería que implementa la empresa para gestionar sus riesgos, específicamente para incendios, derrames, nubes tóxicas y explosiones.

5. ¿Qué planes están establecidos para evaluar la sostenibilidad de las empresas del sector químico?

En cuanto al grupo de Producción y Consumo Sostenible se tiene un enfoque de atención generalizado a todos los sectores, sin diferenciar por temáticas.

6. ¿Se le está haciendo seguimiento a las industrias químicas, en cuanto al cumplimiento legal del manejo de los productos y sustancias químicas en el municipio de Medellín?; Un ejemplo es el adecuado etiquetado de los productos químicos para aquellos que cumplen los criterios de peligrosos regulado por el decreto 1496 de 2018.

Como se comentó en la pregunta 5, desde la Unidad de Control y Vigilancia, se realizan las respectivas visitas en el cumplimiento del rol de autoridad ambiental. El grupo de Producción y Consumo Sostenible y la Unidad de Gestión del Riesgo, realizan acciones con un enfoque de Gestión del Riesgo y de asesoría, soportados en los tres procesos de la gestión (conocimiento y reducción del riesgo, manejo del desastre).

Es importante mencionar que como resultado de las visitas realizadas por la Unidad de Gestión del Riesgo, se envía un informe u oficio donde se realizan los respectivos requerimientos (cuando aplique) y recomendaciones en cuanto al almacenamiento (características del sitio de almacenamiento de las SQP, sistemas de contención de derrames, almacenamiento mediante criterios de compatibilidad química, señalización acorde con la clases de peligrosidad de las sustancias, hojas o fichas de datos de seguridad en sitio, entre otros), disposición final de residuos peligrosos, como envases contaminados con SQP y las SQP en desuso, también en el tema de prevención y control de derrames solicitando la presentación del Plan de contingencia para el manejo de derrame de hidrocarburos y sustancias nocivas que establece el artículo 2.2.3.3.4.14 Plan de contingencia para el manejo de derrame de hidrocarburos y/o sustancias nocivas del Decreto 1076 de 2015, modificado por el artículo 7 del Decreto 50 de 2018. 


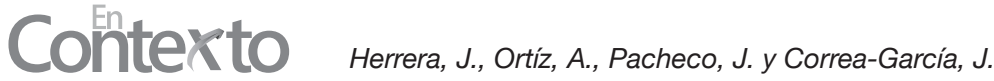

Respecto al Control y vigilancia es importante mencionar que, por competencias asignadas a las autoridades ambientales, no se realizan procesos de control y vigilancia de la normatividad asociada al manejo de sustancias químicas peligrosas excepto para los residuos peligrosos. Por lo anterior, el etiquetado bajo el Sistema Globalmente Armonizado de clasificación y etiquetado de productos químicos no es objeto de seguimiento, pero si de acompañamiento en temas formativos.

\section{Anexo 4. Glosario de indicadores del Global Reporting Initiative (2016)}

\begin{tabular}{c|l}
\hline 1 & Principios para la elaboración de informes \\
\hline 2 & Uso de los Estándares GRI para la elaboración de informes de sostenibilidad \\
\hline $102-1$ & Redacción de declaraciones relacionadas con el uso de los Estándares GRI \\
\hline $102-2$ & Actividades, marcas, productos y servicios \\
\hline $102-3$ & Ubicación de la sede \\
\hline $102-4$ & Ubicación de las operaciones \\
\hline $102-5$ & Propiedad y forma jurídica \\
\hline $102-6$ & Mercados servidos \\
\hline $102-7$ & Tamaño de la organización \\
\hline $102-8$ & Información sobre empleados y otros trabajadores \\
\hline $102-9$ & Cadena de suministro \\
\hline $102-10$ & Cambios significativos en la organización y su cadena de suministro \\
\hline $102-11$ & Principio o enfoque de precaución \\
\hline $102-12$ & Iniciativas externas \\
\hline $102-13$ & Afiliación a asociaciones \\
\hline $102-14$ & Declaración de altos ejecutivos responsables de la toma de decisiones \\
\hline $102-15$ & Principales impactos, riesgos y oportunidades \\
\hline $102-16$ & Valores, principios, estándares y normas de conducta \\
\hline $102-17$ & Mecanismos de asesoramiento y preocupaciones éticas \\
\hline $102-18$ & Estructura de gobernanza \\
\hline $102-19$ & Delegación de autoridad \\
\hline $102-20$ & Responsabilidad a nivel ejecutivo de temas económicos, ambientales y sociales \\
\hline $102-21$ & Consulta a grupos de interés sobre temas económicos, ambientales y sociales \\
\hline $102-22$ & Composición del máximo órgano de gobierno y sus comités \\
\hline 10 & Presidente del máximo órgano de gobierno \\
\hline 10
\end{tabular}




\begin{tabular}{|c|c|}
\hline $102-24$ & Nominación y selección del máximo órgano de gobierno \\
\hline $102-25$ & Conflictos de intereses \\
\hline $102-26$ & $\begin{array}{l}\text { Función del máximo órgano de gobierno en la selección de objetivos, } \\
\text { valores y estrategia }\end{array}$ \\
\hline $102-27$ & Conocimientos colectivos del máximo órgano de gobierno \\
\hline $102-28$ & Evaluación del desempeño del máximo órgano de gobierno \\
\hline $102-29$ & Identificación y gestión de impactos económicos, ambientales y sociales \\
\hline $102-30$ & Eficacia de los procesos de gestión del riesgo \\
\hline $102-31$ & Evaluación de temas económicos, ambientales y sociales \\
\hline $102-32$ & $\begin{array}{l}\text { Función del máximo órgano de gobierno en la elaboración de informes } \\
\text { de sostenibilidad }\end{array}$ \\
\hline $102-33$ & Comunicación de preocupaciones críticas \\
\hline $102-34$ & Naturaleza y número total de preocupaciones críticas \\
\hline $102-35$ & Políticas de remuneración \\
\hline $102-36$ & Proceso para determinar la remuneración \\
\hline $102-37$ & Involucramiento de los grupos de interés en la remuneración \\
\hline $102-38$ & Ratio de compensación total anual \\
\hline $102-39$ & Ratio del incremento porcentual de la compensación total anual \\
\hline $102-40$ & Lista de grupos de interés \\
\hline $102-41$ & Acuerdos de negociación colectiva \\
\hline $102-42$ & Identificación y selección de grupos de interés \\
\hline $102-43$ & Enfoque para la participación de los grupos de interés \\
\hline $102-44$ & Temas y preocupaciones clave mencionados \\
\hline $102-45$ & Entidades incluidas en los estados financieros consolidados \\
\hline $102-46$ & Definición de los contenidos de los informes y las Coberturas del tema \\
\hline $102-47$ & Lista de temas materiales \\
\hline $102-48$ & Reexpresión de la información \\
\hline $102-49$ & Cambios en la elaboración de informes \\
\hline $102-50$ & Período objeto del informe \\
\hline $102-51$ & Fecha del último informe \\
\hline $102-52$ & Ciclo de elaboración de informes \\
\hline $102-53$ & Punto de contacto para preguntas sobre el informe \\
\hline $102-54$ & Declaración de elaboración del informe de conformidad con los Estándares GRI \\
\hline $102-55$ & Índice de contenidos GRI \\
\hline $102-56$ & Verificación externa \\
\hline $103-1$ & Explicación del tema material y su Cobertura \\
\hline
\end{tabular}




\begin{tabular}{|c|c|}
\hline $103-2$ & El enfoque de gestión y sus componentes \\
\hline $103-3$ & Evaluación del enfoque de gestión \\
\hline $201-1$ & Valor económico directo generado y distribuido \\
\hline $201-2$ & $\begin{array}{l}\text { Implicaciones financieras y otros riesgos y oportunidades derivados del } \\
\text { cambio climático }\end{array}$ \\
\hline $201-3$ & Obligaciones del plan de beneficios definidos y otros planes de jubilación \\
\hline $201-4$ & Asistencia financiera recibida del gobierno \\
\hline $202-1$ & Ratio del salario de categoría inicial estándar por sexo frente al salario mínimo local \\
\hline $202-2$ & Proporción de altos ejecutivos contratados de la comunidad local \\
\hline $203-1$ & Inversiones en infraestructuras y servicios apoyados \\
\hline $203-2$ & Impactos económicos indirectos significativos \\
\hline $204-1$ & Proporción de gasto en proveedores locales \\
\hline $205-1$ & Operaciones evaluadas para riesgos relacionados con la corrupción \\
\hline $205-2$ & Comunicación y formación sobre políticas y procedimientos anticorrupción \\
\hline $205-3$ & Casos de corrupción confirmados y medidas tomadas \\
\hline $206-1$ & $\begin{array}{l}\text { Acciones jurídicas relacionadas con la competencia desleal y las prácticas } \\
\text { monopólicas y contra la libre competencia }\end{array}$ \\
\hline $301-1$ & Materiales utilizados por peso o volumen \\
\hline $301-2$ & Insumos reciclados \\
\hline $301-3$ & Productos reutilizados y materiales de envasado \\
\hline $302-1$ & Consumo energético dentro de la organización \\
\hline $302-2$ & Consumo energético fuera de la organización \\
\hline $302-3$ & Intensidad energética \\
\hline $302-4$ & Reducción del consumo energético \\
\hline $302-5$ & Reducción de los requerimientos energéticos de productos y servicios \\
\hline $303-1$ & Interacción con el agua como recurso compartido \\
\hline $303-2$ & Gestión de los impactos relacionados con los vertidos de agua \\
\hline $303-3$ & Extracción de agua \\
\hline $303-4$ & Vertidos de agua \\
\hline $303-5$ & Consumo de agua \\
\hline $304-1$ & $\begin{array}{l}\text { Centros de operaciones en propiedad, arrendados o gestionados ubicados dentro } \\
\text { de o junto a áreas protegidas o zonas de gran valor para la biodiversidad fuera de } \\
\text { áreas protegidas }\end{array}$ \\
\hline $304-2$ & $\begin{array}{l}\text { Impactos significativos de las actividades, los productos y los servicios en } \\
\text { la biodiversidad }\end{array}$ \\
\hline $304-3$ & Hábitats protegidos o restaurados \\
\hline
\end{tabular}




\begin{tabular}{|c|c|}
\hline $304-4$ & $\begin{array}{l}\text { Especies que aparecen en la Lista Roja de la UICN y en listados nacionales de } \\
\text { conservación cuyos hábitats se encuentren en áreas afectadas por las operaciones }\end{array}$ \\
\hline $305-1$ & Emisiones directas de GEI (alcance 1) \\
\hline $305-2$ & Emisiones indirectas de GEI al generar energía (alcance 2) \\
\hline $305-3$ & Otras emisiones indirectas de GEI (alcance 3) \\
\hline $305-4$ & Intensidad de las emisiones de GEI \\
\hline $305-5$ & Reducción de las emisiones de GEI \\
\hline $305-6$ & Emisiones de sustancias que agotan la capa de ozono (SAO) \\
\hline $305-7$ & $\begin{array}{l}\text { Óxidos de nitrógeno (NOX), óxidos de azufre (SOX) y otras emisiones significativas } \\
\text { al aire }\end{array}$ \\
\hline $306-1$ & Vertido de aguas en función de su calidad y destino \\
\hline $306-2$ & Residuos por tipo y método de eliminación \\
\hline $306-3$ & Derrames significativos \\
\hline $306-4$ & Transporte de residuos peligrosos \\
\hline $306-5$ & Cuerpos de agua afectados por vertidos de agua y/o escorrentías \\
\hline $307-1$ & Incumplimiento de la legislación y normativa ambiental \\
\hline $308-1$ & $\begin{array}{l}\text { Nuevos proveedores que han pasado filtros de selección de acuerdo con } \\
\text { los criterios ambientales }\end{array}$ \\
\hline $308-2$ & Impactos ambientales negativos en la cadena de suministro y medidas tomadas \\
\hline $401-1$ & Nuevas contrataciones de empleados y rotación de personal \\
\hline $401-2$ & $\begin{array}{l}\text { Prestaciones para los empleados a tiempo completo que no se dan a los empleados } \\
\text { a tiempo parcial o temporales }\end{array}$ \\
\hline $401-3$ & Permiso parental \\
\hline $402-1$ & Plazos de aviso mínimos sobre cambios operacionales \\
\hline $403-1$ & Sistema de gestión de la salud y la seguridad en el trabajo \\
\hline $403-2$ & Identificación de peligros, evaluación de riesgos e investigación de incidentes \\
\hline $403-3$ & Servicios de salud en el trabajo \\
\hline $403-4$ & $\begin{array}{l}\text { Participación de los trabajadores, consultas y comunicación sobre salud y seguridad } \\
\text { en el trabajo }\end{array}$ \\
\hline $403-5$ & Formación de trabajadores sobre salud y seguridad en el trabajo \\
\hline $403-6$ & Fomento de la salud de los trabajadores \\
\hline $403-7$ & $\begin{array}{l}\text { Prevención y mitigación de los impactos en la salud y la seguridad de los trabajadores } \\
\text { directamente vinculados con las relaciones comerciales }\end{array}$ \\
\hline $403-8$ & Cobertura del sistema de gestión de la salud y la seguridad en el trabajo \\
\hline $403-9$ & Lesiones por accidente laboral \\
\hline $403-10$ & Dolencias y enfermedades laborales \\
\hline
\end{tabular}




\begin{tabular}{|c|c|}
\hline $404-1$ & Media de horas de formación al año por empleado \\
\hline $404-2$ & $\begin{array}{l}\text { Programas para mejorar las aptitudes de los empleados y programas de ayuda } \\
\text { a la transición }\end{array}$ \\
\hline $404-3$ & $\begin{array}{l}\text { Porcentaje de empleados que reciben evaluaciones periódicas del desempeño } \\
\text { y desarrollo profesional }\end{array}$ \\
\hline $405-1$ & Diversidad en órganos de gobierno y empleados \\
\hline $405-2$ & Ratio del salario base y de la remuneración de mujeres frente a hombres \\
\hline $406-1$ & Casos de discriminación y acciones correctivas emprendidas \\
\hline $407-1$ & $\begin{array}{l}\text { Operaciones y proveedores cuyo derecho a la libertad de asociación y negociación } \\
\text { colectiva podría estar en riesgo }\end{array}$ \\
\hline $408-1$ & Operaciones y proveedores con riesgo significativo de casos de trabajo infantil \\
\hline $409-1$ & $\begin{array}{l}\text { Operaciones y proveedores con riesgo significativo de casos de trabajo forzoso } \\
\mathrm{u} \text { obligatorio }\end{array}$ \\
\hline $410-1$ & Personal de seguridad capacitado en políticas o procedimientos de derechos humanos \\
\hline $411-1$ & Casos de violaciones de los derechos de los pueblos indígenas \\
\hline $412-1$ & $\begin{array}{l}\text { Operaciones sometidas a revisiones o evaluaciones de impacto sobre los } \\
\text { derechos humanos }\end{array}$ \\
\hline $412-2$ & Formación de empleados en políticas o procedimientos sobre derechos humanos \\
\hline $412-3$ & $\begin{array}{l}\text { Acuerdos y contratos de inversión significativos con cláusulas sobre derechos } \\
\text { humanos o sometidos a evaluación de derechos humanos }\end{array}$ \\
\hline $413-1$ & $\begin{array}{l}\text { Operaciones con participación de la comunidad local, evaluaciones del impacto } \\
\text { y programas de desarrollo }\end{array}$ \\
\hline $413-2$ & $\begin{array}{l}\text { Operaciones con impactos negativos significativos -reales y potenciales- en las } \\
\text { comunidades locales }\end{array}$ \\
\hline $414-1$ & $\begin{array}{l}\text { Nuevos proveedores que han pasado filtros de selección de acuerdo con los } \\
\text { criterios sociales }\end{array}$ \\
\hline $414-2$ & Impactos sociales negativos en la cadena de suministro y medidas tomadas \\
\hline $415-1$ & Contribuciones a partidos y/o representantes políticos \\
\hline $416-1$ & $\begin{array}{l}\text { Evaluación de los impactos en la salud y seguridad de las categorías de productos } \\
\text { o servicios }\end{array}$ \\
\hline $416-2$ & $\begin{array}{l}\text { Casos de incumplimiento relativos a los impactos en la salud y seguridad de las } \\
\text { categorías de productos y servicios }\end{array}$ \\
\hline $417-1$ & Requerimientos para la información y el etiquetado de productos y servicios \\
\hline $417-2$ & $\begin{array}{l}\text { Casos de incumplimiento relacionados con la información y el etiquetado de } \\
\text { productos y servicios }\end{array}$ \\
\hline $417-3$ & Casos de incumplimiento relacionados con comunicaciones de marketing \\
\hline $418-1$ & $\begin{array}{l}\text { Reclamaciones fundamentadas relativas a violaciones de la privacidad del cliente } \\
\text { y pérdida de datos del cliente }\end{array}$ \\
\hline $419-1$ & Incumplimiento de las leyes y normativas en los ámbitos social y económico \\
\hline
\end{tabular}

